San Jose State University

SJSU ScholarWorks

Master's Theses

Master's Theses and Graduate Research

1991

\title{
Effectiveness of a culturally modified educational program on control of type II diabetes in Mexican-Americans
}

Carmen Takacs

San Jose State University

Follow this and additional works at: https://scholarworks.sjsu.edu/etd_theses

\section{Recommended Citation}

Takacs, Carmen, "Effectiveness of a culturally modified educational program on control of type II diabetes in Mexican-Americans" (1991). Master's Theses. 219.

DOI: https://doi.org/10.31979/etd.3qvf-ej4q

https://scholarworks.sjsu.edu/etd_theses/219

This Thesis is brought to you for free and open access by the Master's Theses and Graduate Research at SJSU ScholarWorks. It has been accepted for inclusion in Master's Theses by an authorized administrator of SJSU ScholarWorks. For more information, please contact scholarworks@sjsu.edu. 


\section{INFORMATION TO USERS}

This manuscript has been reproduced from the microfilm master. UMI films the text directly from the original or copy submitted. Thus, some thesis and dissertation copies are in typewriter face, while others may be from any type of computer printer.

The quality of this reproduction is dependent upon the quality of the copy submitted. Broken or indistinct print, colored or poor quality illustrations and photographs, print bleedthrough, substandard margins, and improper alignment can adversely affect reproduction.

In the unlikely event that the author did not send UMI a complete manuscript and there are missing pages, these will be noted. Also, if unauthorized copyright material had to be removed, a note will indicate the deletion.

Oversize materials (e.g., maps, drawings, charts) are reproduced by sectioning the original, beginning at the upper left-hand corner and continuing from left to right in equal sections with small overlaps. Each original is also photographed in one exposure and is included in reduced form at the back of the book.

Photographs included in the original manuscript have been reproduced xerographically in this copy. Higher quality 6" x 9 " black and white photographic prints are available for any photographs or illustrations appearing in this copy for an additional charge. Contact UMI directly to order.

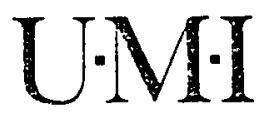




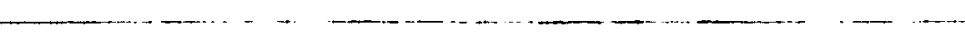


Order Number 1345826

Effectiveness of a culturally modified educational program on control of type II diabetes in Mexican-Americans

Takacs, Carmen, M.S.

San Jose State University, 1991

Copyright (C)1992 by Takacs, Carmen. All rights reserved.

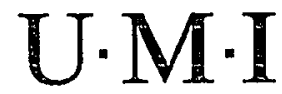

300 N. Zeeb Rd.

Ann Arbor, MI 48106 


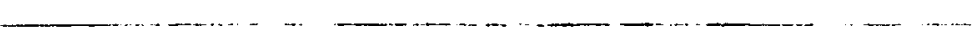

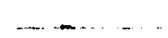




\title{
EFFECTIVENESS OF A CULTURALLY MODIFIED EDUCATIONAL PROGRAM ON CONTROL OF TYPE II DIABETES IN MEXICAN-AMERICANS
}

\author{
A Thesis \\ Presented to \\ The Faculty of the Department of Nursing \\ San Jose State University \\ In Partial Fulfillment \\ of the Requirements for the Degree \\ Master of Science
}

By

Carmen Takacs

August, 1991 
APPROVED FOR THE DEPARTMENT OF NURSING

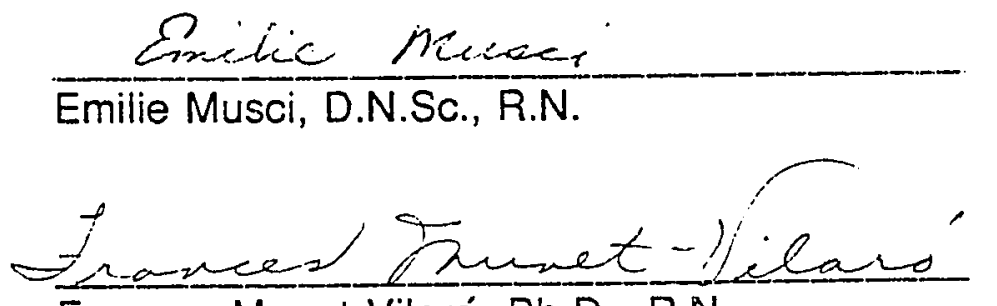

Frances Munet-Vilaró, Ph.D., R.N.

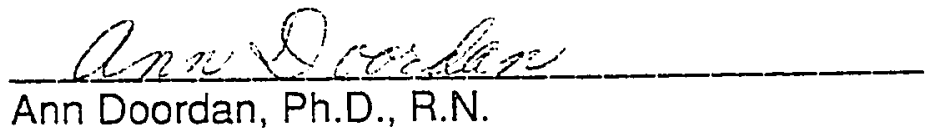

APPROVED FOR THE UNIVERSITY

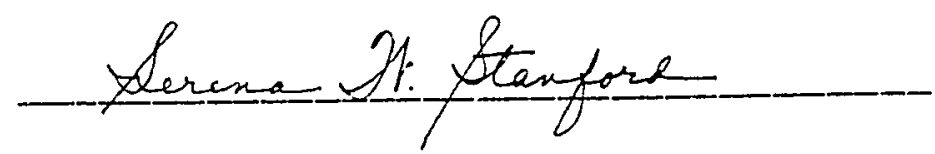




\section{ABSTRACT \\ EFFECTIVENESS OF A CULTURALLY MODIFIED EDUCATIONAL PROGRAM ON CONTROL OF TYPE II DIABETES IN MEXICAN-AMERICANS \\ by Carmen Takacs}

This study used a quasi-experimental design to assess whether culturally modified teaching is more effective than traditional teaching in helping Mexican-American clients' control type II diabetes. A convenience sample included aduit Mexican-Americans with type II diabetes from 2 agencies in an urban area. Self-care attitudes $(\underline{n}=30$ ) of a group receiving culturally sensitive education were compared to self-care attitudes of a group $(\underline{n}=30)$ receiving education without cultural adaptation. The Diabetes Health Belief Scale measured Mexican-American health beliefs affecting self-care attitudes about diabetes care. The t-test indicated a highly significant difference in 5 of the health belief subscale scores: (a) General Health Motivation ( $p<.001$ ), (b) Treatment Benefit $(\underline{p}<.001)$, (c) Susceptibility ( $\underline{p}=.007$ ), (d) Cues to Action ( $\underline{p}<.001$ ), and $(e)$ Structural Elements $(\underline{p}<.001)$. Familial predisposition, physical complications, social and economic impact of diabetes were factors evaluated after implementing culturally modified classes for the two groups. Study results demonstrated that further study in understanding cultural practices, beliefs, and values is necessary for nurses and health professionals working with diabetic Mexican-American clients to improve diabetes morbidity. 


\section{ACKNOWLEDGEMENTS}

I wish to acknowledge Sue Ann Kelly, Education Director of the Diabetes Society of Santa Clara County, for her encouragement to pursue this study and the participants of this study who, through their cooperation, made this study possible. A special word of thanks to my graduate advisor, Dr. Emilie Musci, for her support and guidance. I also wish to thank the graduate faculty of the Department of Nursing for their support and encouragement during my graduate education. I am grateful to my children, Yolanda, John, and Jimmy, for their understanding and their prayers. Most importantly, I sincerely thank my husband, Joseph, for his unselfish time, constant encouragement, and enduring support throughout my graduate studies. 


\section{TABLE OF CONTENTS}

Page

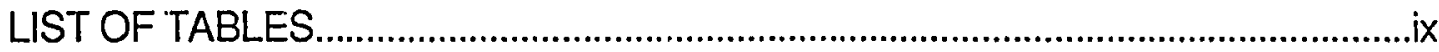

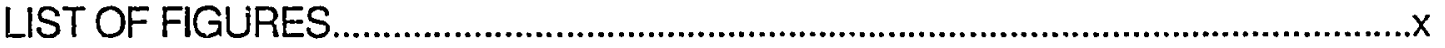

Chapter

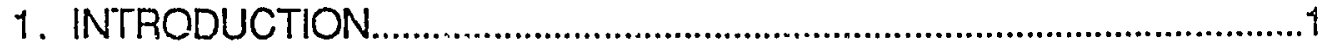

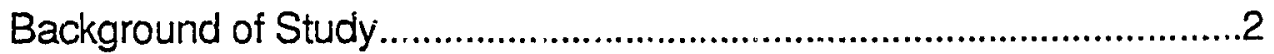

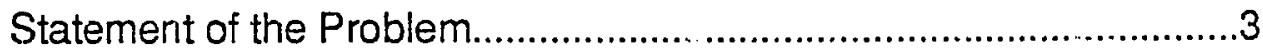

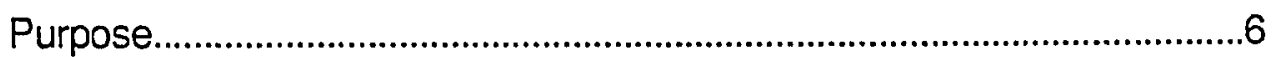

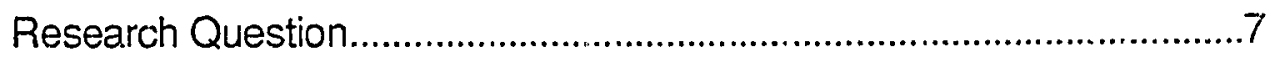

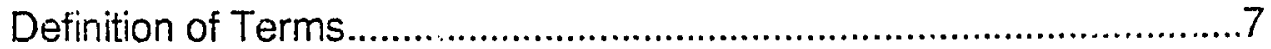

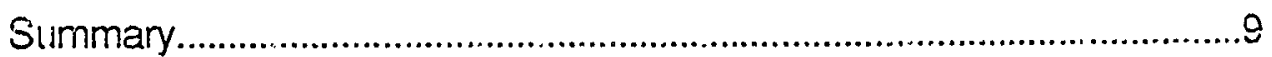

2. CONCEPTUAL FRAMEWORK AND REVIEW

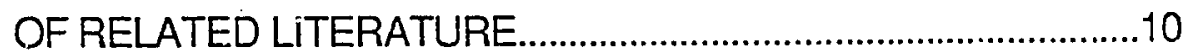

Conceptual Framework...................................................................10

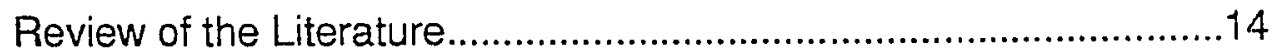

Statistical Demographics...............................................................14

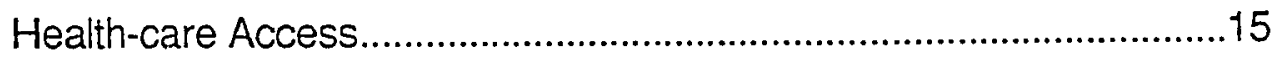

Diabetes Related Programs...........................................................17

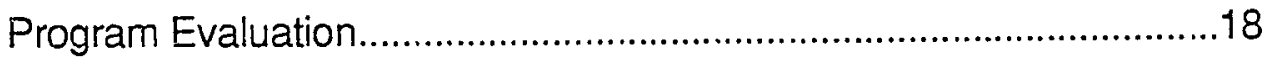

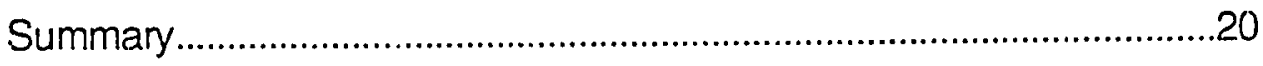




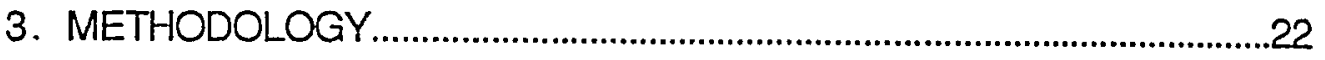

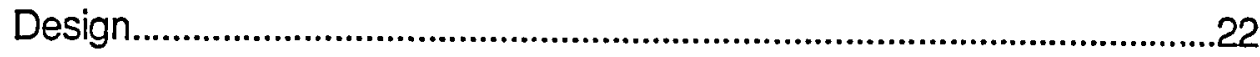

Approval for Human Subjects Study ............................................22

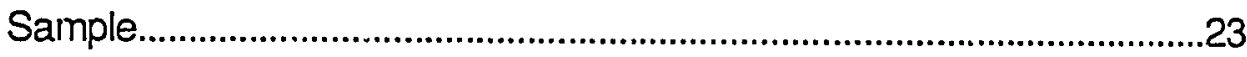

Culturally Modified Diabetes Class...............................................24

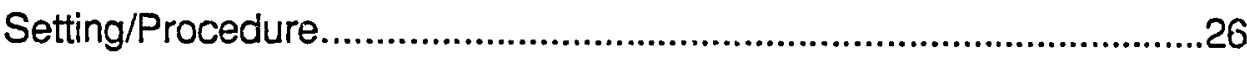

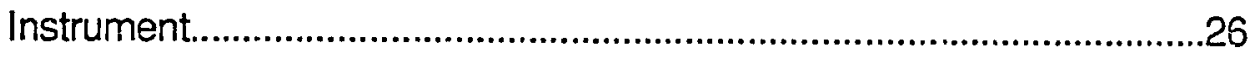

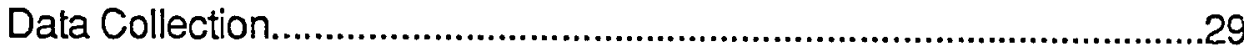

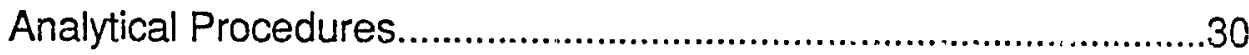

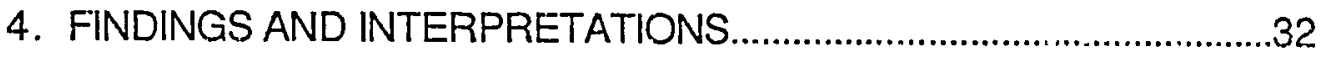

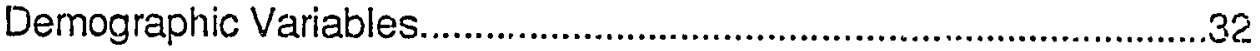

Diabetes Health Beliefs Findings

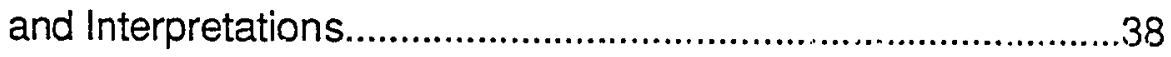

Findings Related to General Health Motivation........................38

Findings Related to Treatment Benefit.......................................41

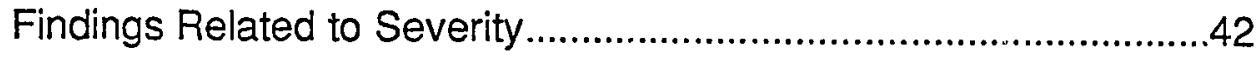

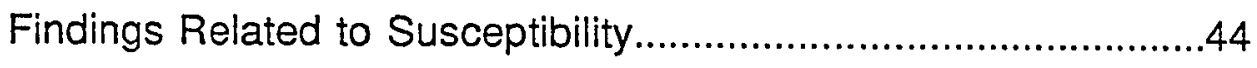

Findings Related to Psychological Barriers...............................45

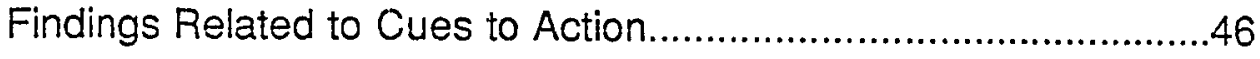

Findings Related to Structural Elements..................................47

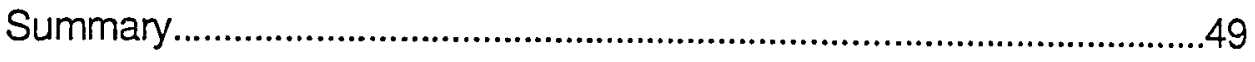




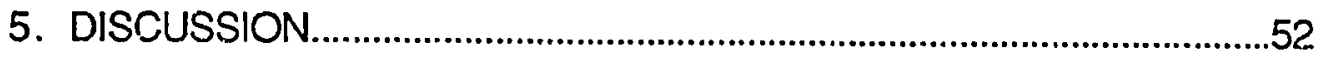

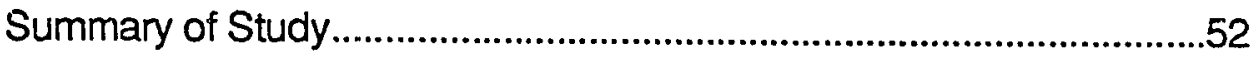

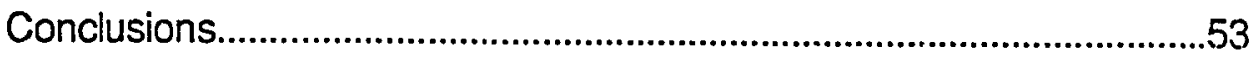

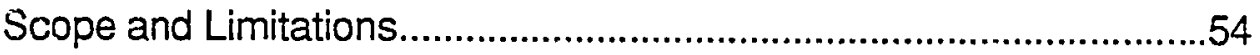

Recommendations for Further Study .......................................55

Recommendations Related to Nursing.......................................55

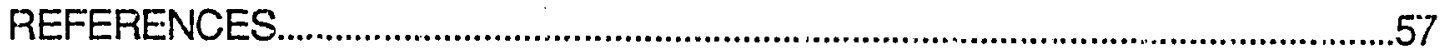

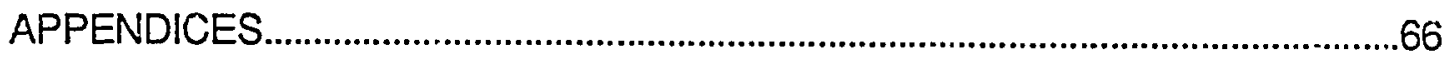

A. Approval by Human Subjects Institutional

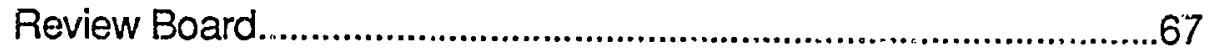

B. Consent Form for Experimental and

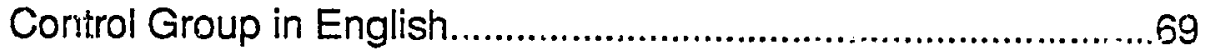

C. Consent Form for Experimental and

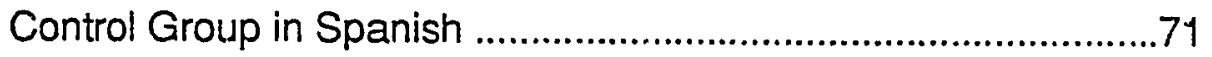

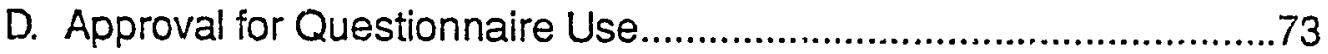

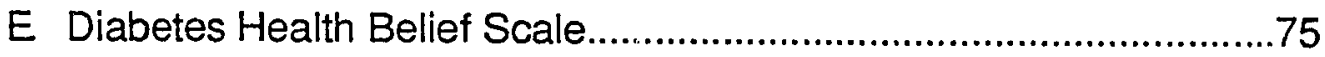

F. Approval of Spanish Translation

by Foreign Languages Department............................................78

G Diabetes Heaith Belief Scale Spanish Translation..................80

H. Scoring of the Diabetes Health Belief Scale............................84

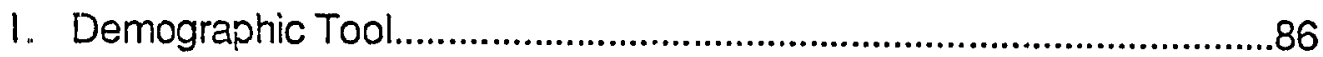


J. Diabetes Society of Santa Clara County

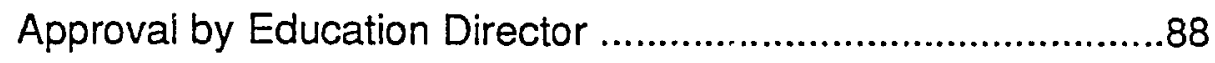

K. Council of Aging of Santa Clara County

Approval by Site Administrator................................................90 


\section{LIST OF TABLES}

Table

1. Factor Reliability Coefficients Cronbach Alpha of the Spanish Version of the DHBS..........................................30

2. Selected Demographic Indices.......................................................33

3. Summary of Diabetes Family History

Frequency of Diabetes in the Families of the Experimental, Control, and Combined Samples.

4. Summary of Diabetes Complications

and/or symptoms, Frequencies, within the Experimental, Control, and Combined

Samples.

5. Experimental and Control Group Means (m) of Attitudes, Standard Deviations (SD), and $\mathrm{t}$-values for Diabetes Health Belief Scale Score. 


\section{LIST OF FIGURES}

Figure

Page

1. The Health Belief Model..................................................................11 


\section{Chapter 1}

\section{INTRODUCTION}

In the Spring of 1987 the Diabetes Society adapted and translated to Spanish the Anglo-American diabetes education curriculum to meet the cultural needs of the growing MexicanAmerican population. The investigator, in addition to other bilingual-bicultural health professionals, assisted the Diabetes Society with the adaptation of this educational program. The Diabetes Society implemented this program with the Hispanic population in the Fall of 1987. The program consisted of a 3 hour presentation on basic knowledge of diabetes, emphasizing aspects of self-care including diet, exercise, skin and foot care. The program discussed purchasing and preparing low caloric foods including fruits and vegetables. For instance, one of the recommendations was to substitute a very small amount of oil instead of pork fat to prepare refried beans. Food items that are part of the MexicanAmerican diet such as corn tortillas; rice, and refried beans were integrated into the presentation. The class was taught by bilingualbicultural health professionals. Teaching was supplemented by transparencies, charts, and printed materials (in Spanish). Other techniques used were demonstrations on blood sugar monitoring and low caloric nutritious food items. Throughout the class, educational strategies appropriate to the culture were used. For example, 
demonstrations and educational materials used during the class or distributed to the clients were tailored to meet the traditional life style of the Mexican-American population. Although many MexicanAmerican clients have been exposed to these culturaliy modified classes, no evaluative study has been completed to determine the effectiveriess of this program.

\section{Background of Study}

Patient education has been supported in the literature as an essential component of nursing care (Barlett, 1983; Graber, Christman, Alogna \& Davidson, 1977). For people with a chronic disease such as diabetes, education is an important part of effective disease management. In order for patients to treat diabetes successfully, they need to be motivated towards positive self-care attitudes through comprehensive educational programs. Health professionals with an interest in diabetes are aware of the impact of this disease on Mexican-Americans living in the United States.

According to the National Diabetes Advisory Board (1984), educational programs should be appropriate for the specified target audience, taking into consideration the type and duration of diabetes and the age and learning ability of the individual. One important element of a health educational program is meeting the cultural needs of different ethnic populations. Thus, one important aspect of the diabetes education for Mexican-Americans is modified programs tailored to meet their cultural needs. Culturally sensitive diabetes 
education is fundamental to improving the quality of health care provided to the Mexican-American client with diabetes.

Statement of the Problem

Over the past several years the rate of diabetes among Hispanics has increased significantly in the United States. Hispanics in America constitute over 19 million people (U. S. Bureau of the Census, 1988). The majority of this number are MexicanAmericans, with a population of 12.1 million or $62.3 \%$ of the total Hispanic population. California has the nation's largest MexicanAmerican population, followed by Texas. Of all Hispanics in the United Sates, $55 \%$ reside in these two states (U. S. Bureau of the Census, 1988). Studies show that the incidence of diabetes among Mexican-Americans is 2 to $21 / 2$ times higher than in the general population (Diehl \& Stern, 1989).

One fifth of Hispanic adults, 2.6 million people, are medically disadvantaged (U. S. Bureau of the Census, 1988). Studies indicate that Mexican-Americans either lack health insurance, do not have a regular source of medical care because of financial problems, or do not know where to seek care (Andersen, Zelman-Lewis, Giachello, Aday \& Chiu, 1981; Burma, 1970). Due to their minority status, cultural distinctness, and generally low socioeconomic status, generations of Mexican-Americans experience social and environmental stress, generally correlated with increased morbidity and mortality (U.S. Department of Health and Human Services, 1986). 
Type $1 /$ diabetes mellitus, also known as noninsulin dependent diabetes mellitus (NIDDM), is a disease of major proportions in the United States and is a major health problem in the Hispanic community. Diabetes constitutes a major health risk because it affects virtually all the systems of the body when not controlled. The Nationai Diabetes Data Group (1984) reported that the high numbers of undiagnosed and uncontrolled cases make the Hispanic population vulnerable to disease complications such as retinopathy and nephropathy.

Clinical observation and results from Phase 1 of the San Antonio Heart Study 1979-1984 revealed that Mexican-Americans suffer frorn type 11 diabetes to a higher degree in comparison to the general United States population. This predisposition was generally attributed to: (a) higher rates of obesity, (b) particularly in women, (c) lower socioeconomic status, (d) stress, and (e) a genetic susceptibility (Lytt et al., 1984; Schade, 1982; Stern, Pugh, PartenGaskill \& Hazuda, 1982). Phase II of the San Antonio Heart Study, which began in 1984 and is currently in progress, will provide estimates of diabetes incidence in Mexican-Americans for the first time (Diehl \& Stern, 1989).

Further research done by the San Antonio Heart Study showed that type II diabetes is metabolically more severe in MexicanAmericans. The results of one-hour fasting blood glucose tests revealed that 1 of 3 Mexican-Americans with diabetes fell into the severe category, compared with $10 \%$ of Non-Hispanic whites 
(Haffner, Rosenthal, Hazuda, Stern \& Franco, 1984). Continuing investigation by the San Antonio Heart Study showed a sixfold increased risk of end-stage renal disease due to diabetic nephropathy among Mexican-Americans compared with AngloAmericans (Pugh, Stern, Haffner, Eifler, Zapata, 1988). The risk of retinopathy was found to be 3 times more common in the Hispanic population when compared with the Anglo population (Haffner et al., 1988).

Factors that may influence the occurrence of diabetes among Mexican-Americans are obesity and genetics (Lytt et al., 1984; Mueller et al., 1983). Although obesity does not appear to account completely for the excess of diabetes among Mexican-Americans, the San Antonio Heart Studies revealed higher rates of diabetes among the obese (Stern et al., 1982). The people studied in the San Antonio "barrio" exhibited a higher degree of obesity and diabetes than either the more affluent Mexican-Americans or AngloAmericans. These studies found that even lean Mexican-Americans had more diabetes when compared to their lean Anglo-American counterparts.

Other research with the San Antonio Heart Studies (Lytt et al., 1984) confirmed higher rates of NIDDM within low-income "barrio" Mexican-Americans who have a higher percentage of native American ancestry as compared with affluent suburban Mexican-Americans. Diabetes among Mexican-Americans has created a significant health problem within the American Health Care System as evidenced by 
the statistical increase of this population and their higher incidence of diabetes.

\section{Purpose}

The purpose of this study was to assess the effectiveness of culturally modified diabetic classes on the health beliefs affecting self-care attitudes of the Mexican-American client. Research indicates that the integration of transcultural concepts and nursing care delivery is fundamental to improving the quality of nursing care provided to culturally diverse populations (Anthony-Tkach, 1986; Leininger, 1989; Reinert, 1988). Anthony-Tkach (1986) proposed that since America is a pluralistic society, health professionals need to be prepared to present health care in ways that are appropriate to various cultures. She also stated that cultural identification gives knowledge from which nurses can anticipate client differences in: (a) values, (b) religion, (c) dietary practices, (d) family life patterns, (e) beliefs, and (f) practices related to health and illness.

Research on the effectiveness of a culturally sensitive educational program for Mexican-Americans is needed in order to identify health beliefs affecting self-care attitudes of this population after exposure to these classes. The data will be valuable for better understanding of the complex problem of diabetes management among this group. Researchers suggest that changes in the educational and opportunity structure of the health 
care system are necessary if the health care behavior of culturally different populations is to be improved.

The goal of culturally modified diabetic education is to be able to modify the group's behavior. However, effective education takes time, and behavioral changes can only be measured over a long period of time. The results will not be immediately evidenced. The ultimate effects from education via a culturally modified program will be a decrease in the incidence and prevalence of the disease and subsequent human and economic cost.

Research Question

Is there a difference in health beliefs affecting self-care attitudes towards diabetes control between Mexican-Americans who attend a culturaliy modified diabetes class and those who do not attend the class?

\section{Definition of Terms}

For the purpose of this study, the following terms and definitions were used:

1. Health education is a set of strategies or learning experiences designed to bring about voluntary adjustment of behavior conducive to health (Green, Lewis \& Levine, 1980).

2. Culturally modified diabetes education class is a health program where educationally appropriate and culturally sensitive health education materials are developed in coordination with relevant ethnic groups needs and cultural practices. 
3. Type II Diabetes Mellitus is a chronic endocrine disorder which usually affects adults over the age of 30 . The results of the body's inability to use insulin effectively are disorders of fat, carbohydrate, and protein metabolism (U.S. Department of Health and Human Services, 1986).

4. Mexican-American is a person of Mexican descent with Hispanic cultural heritage. For the purpose of this study, MexicanAmericans with low educational and socioeconomic levels, as defined by the U. S. Bureau of the Census (1988), were studied.

5. Health Belief Model is a model based on psychological and behavioral theories, stating that health behavior depends mainly upon two variables: (a) the value placed by an individual on a particular goal, and (b) the individual's estimate of the likelihood that a given action will achieve that goal (Becker \& Janz, 1985).

6. Self-care attitudes are health and lifestyle behaviors undertaken by the Mexican-American client for the purpose of controlling diabetes and/or preventing its complications.

7. Diabetes management is the way in which a patient applies a regimen related to: (a) insulin administration and dosage, (b) urine testing, (c) dietary modification, and (d) skin and foot care. The diabetes regimen is monitored by blood glucose levels.

8. Compliance is the patient's action to manage the disease by adhering to the prescribed regimen. 


\section{Summary}

Hispanics, the majority of whom are of Mexican origin, are the fastest growing minority in America. Of the total population in the United States, $20 \%$ are Hispanic and most Hispanics are of Mexican descent. The rate of diabetes among Mexican-Americans in the United States has increased dramatically. Today Mexican-Americans are about $21 / 2$ times more likely to develop diabetes than NonHispanics. The health care delivery system has lacked the means to give minority clients comprehensive health care sensitive to cultural needs and economic situation. The combination of the Mexican-American population increase and the high incidence of diabetes in this population are creating a significant health problem for the American health care system. 
Chapter 2

CONCEPTUAL FRAMEWORK AND REVIEW OF RELATED LITERATURE

Conceptual Framework

The conceptual framework for this study was derived from the Health Belief Model (HBM) (Rosenstock, 1974). The model is a cognitive formulation initially originated by Hochbaum, Kegeles, Leventhal, and Rosenstock in the early 1950's to predict or explain both preventive and compliance oriented health related behaviors. The Health Belief Model is based on psychological and behavioral theories, stating that health behavior depends mainly upon 2 variables: (a) the value placed by an individual on a particular goal, and (b) the individual's estimate of the likelihood that a given action will achieve that goal (Becker \& Janz, 1985).

The health motivation concept was introduced into the model by Becker, Drachman, and Kirscht (1974). Health motivation refers to a person's degree of interest in and concern about health matters. The desire to attain or maintain a positive state of health and to avoid a state of illness is a dimension of health motivation. The major dimensions of the model (Figure 1) that were developed to explain motivation include: (a) the extent to which people believe they are susceptible to a disease (perceived susceptibility), (b) belief in the efficacy or value of a behavior in reducing the threat (perceived benefits), and (c) perceived benefits of certain 


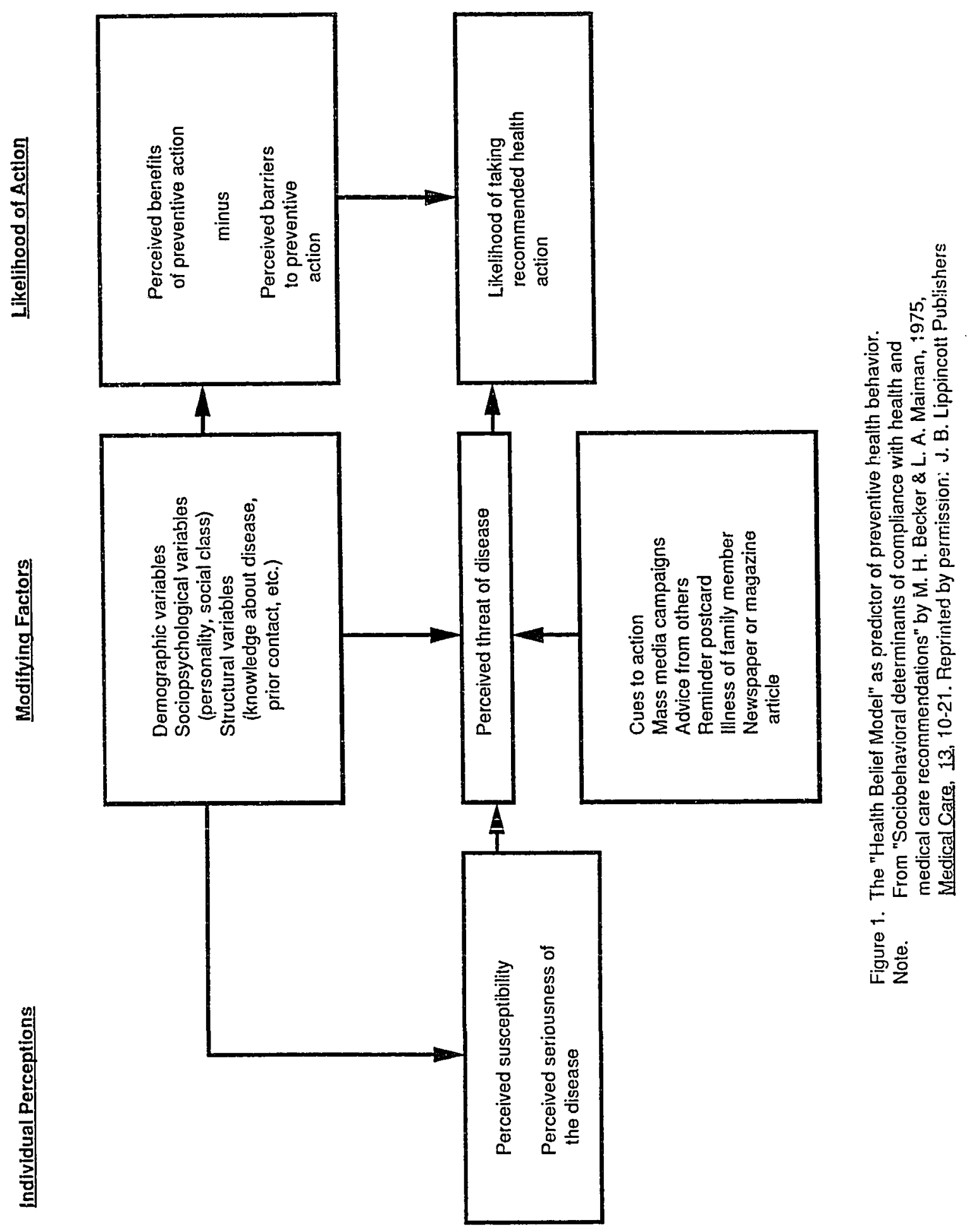


actions reducing susceptibility to or severity of the condition in the light of any perceived barriers (Becker et al., 1974). The model also postulates that a relevant stimulus or "cue to action" must occur to trigger the appropriate health behavior. This stimulus might be internal (e.g., symptoms or bodily states) or external (e.g., health communications or advice from others) (Becker \& Maiman, 1975).

Kasl (1974) suggested reformulation of the model to distinguish chronic disease behavior from acute illness behavior. Chronic disease behavior needs special consideration since it requires the person to: (a) stay in treatment and comply with the regimen although not feeling sick, (b) take medication although no changes in health are felt, (c) follow treatment indefinitely, and (d) do this in a setting that has minimal social and institutional support (Kasl, 1974).

Extensive research now exists linking the HBM dimensions to compliance with regimens for chronic diseases and obesity. The studies involve such behavior as: (a) taking or administering medication, (b) following dietary restrictions, (c) exercising, and (d) keeping clinic appointments (Alogna, 1980; Becker \& Janz, 1985; Becker, Maiman, Kirscht, Haefner \& Drachman, 1977). Review of compliance literature reveals that at least one-third of all patients do not comply with their medical regimens. One-third of all the documerited studies reported a noncompliance rate of $50 \%$ or higher (Alogna, 1980; Ary, Toobert, Wilson \& Glasgow, 1986; BloomCerkoney \& Hart, 1980; Gillum \& Barsky, 1974). 
Rosenstock (1985) stated that compliance with diabetic regimens may be even poorer than with regimens for other conditions. He stated that typically the diabetic regimen is difficult to follow because it consists of an everyday lifelong treatment, requiring complex behavioral changes on the patient's part, such as: (a) dietary modifications, (b) urine or blood testing, (c) daily oral medication or injections, (d) safety measures, and (e) exercise routines. The literature indicates that the diabetic client has a low level of compliance, probably due to this complexity. For example, Bloom-Cerkoney \& Hart (1980) cited several studies reporting urine testing as low as $30 \%$, and diet regimen compliance in the 10 to $35 \%$ range.

The essential relationship between health behavior and symptoms was explained by Kirscht (1974). He pointed out that symptoms may represent a threat to the individual, and the presence of symptoms may arouse health motivation or act as a cue to taking action. The Mexican-American's understanding of illness and subsequent behavior may relate to the attachment of ethnic traditions (Bullough \& Bullough, 1982; Quesada, 1976; Reinert, 1988). Disease prevention is not well understood by the tradition oriented Mexican-American. Bullough \& Bullough (1982) stated that one of the difficulties is a cultural tradition suggesting that bad health, although unpleasant, is something that one endures. In discussing stages of medical interventions by the MexicanAmericans, Quesada (1976) indicated that intervention is considered 
by this group only when certain symptom thresholds are experienced. Cultural beliefs of the Mexican-Americans may reflect on their health views and attitudes which may negatively affect their health care. This influence, in turn, may contribute to the high incidence of diabetes. Mexican-American folk orientation requires the presence of symptoms to diagnose illness, therefore a person who manifests no debilitating symptoms is generally regarded as healthy. This belief results in a delay in seeking medical care, often until the condition becomes life threatening.

Research on how to focus or change existing cultural beliefs to attain positive health outcomes was not found in the literature by the investigator. The Health Belief Model has not developed culturally sensitive concepts relative to different ethnic groups. Harwood (1981) states that people raised with common origins develop a sense of identity and shared standards for behavior. Through experience they often acquire basic concepts and attitudes towards health and illness, reinforcing these concepts through their fundamental styles of communication and behavior.

\section{Review of the Literature \\ Statistical Demegraphics}

The United States has the sixth largest Hispanic population in the world, exceeded only by Mexico, Spain, Colombia, Argentina, and Peru (U. S. Bureau of the Census, 1984). According to the Census Bureau (1988), the Hispanic population numbered 19.4 million, representing $8.1 \%$ of the total United States population. In 1980, the 
Hispanic population represented $6.5 \%$ of the total population. Since the 1980 census, the Hispanic population has increased by $34 \%$ or about 4.8 million persons. The comparable increase for the nonHispanic population was only $7 \%$. About half of the population growth of the Hispanic population resulted from net migration and half from natural increase (U. S. Bureau of the Census, 1988).

\section{Health-care Access}

Mexican-Americans share poverty related health problems that are considered the main cause of poor health among some minority groups. A review of pertinent literature indicates that Mexican. Americans suffer severe health problems not adequately addressed by the health delivery systems (Bullough \& Bullough, 1982; Burma, 1970; Harwood, 1981; Weaver, 1976). These problems are the result of different factors such as: (a) environmental and socioeconomic conditions, (b) the existence of a folk medicine belief system, and (c) limited access to health care (Bullough \& Bullough, 1982; Harwood, 1981; Quesada, 1976; Weaver, 1976).

Data addressing problems of limited access to medical care and health behavior among Mexican-Americans have been documented in the literature since the early 1950's (Saunders, 1954; Weaver 1973). Harwood (1981) and Weaver (1976) discussed both cultural factors and deficits in the health care delivery system that have prevented or discouraged the Mexican-American from seeking appropriate medical care. Quesada (1976) stated that cultural and language differences produce perceptible differences affecting the 
health status of the Mexican-American in terms of access, compliance, and follow-up care in the dominant health care system. However, some researchers believe that strong ethnic beliefs and values do not necessarily limit access to the formal health care system (Gaertsen, Klauber, Rindflesh, Kane \& Gray, 1975). They suggest that sometimes cultural values reinforce rather thar inhibit seeking formal medical care.

More recent research suggested that lack of access to medical care for the Hispanic population of the Southwestern United States ( $83 \%$ Mexican-American) is associated with low levels of income, education, and health insurance coverage (Andersen et al., 1981). The lack of coverage is related to low income and educational levels and to the fact that this population is less likely to be in jobs that provide health care benefits. Andersen et al. (1981) indicated that Hispanics are less likely to see a doctor or have a preventive health examination and much less likely to see a dentist than the general population. The researchers (Andersen et al., 1981) related both levels of perceived need and socioeconomic valuables (particularly education and health insurance coverage) to lower level of physician use. Avoidance of preventive examinations relates more to socioeconomic differences than to perceived need.

The literature revealed that in the past, most MexicanAmericans were poorly educated migratory workers (Bullough \& Bullough, 1982; House Committee on Aging, 1989). Because of the limited access to continuing quality health care, and lower 
education and socioeconomic status, it has been difficult, if not nearly impossible, for this population to benefit from health information and preventive health education. Low education, socioeconomic status and the lack of access to optimal health care have kept this population unaware of basic knowledge of preventive health and self-care, increasing their risk for chronic disease and its complications.

\section{Diabetes Related Programs}

Several years ago new programs were developed on diabetes education in different settings for the Anglo-American population (Etzwiler \& Robb, 1972; Legge, Massey, Vena \& Riely, 1980; Leichter, 1979; Paulozzi, Norman, McMahon \& Connell, 1984), but documentation of these programs for Mexican-Americans is very limited in the literature. A diabetes care program serving preciominantly Mexican-Americans was developed and implemented for nearly 2 decades at the Los Angeles County Hospital (U.S. Department of Health and Human Services, 1986). This program stressed a prevention oriented approach that emphasized: (a) early diagnosis, (b) optimal medical evaluation, (c) patient education, and (d) access to continuing care from a team of trained professionals.

Recently educational programs on diabetes have been culturally adapted and implemented in some communities to meet the needs of Mexican-Americans (Diabetes Society of Santa Clara County, 1987). The Diabetes Society has further organized a Hispanic Diabetes Council to assess needs of the Hispanic diabetic 
and recommend proper interventions. Documented data on development and implementation of culturally modified educational programs on diabetes are extremely limited. Literature documenting diet therapy for minority groups with diabetes is limited (Gohdes, 1988; Hall, 1987; Maras \& Adolphi, 1985). These studies are descriptive in nature, with emphasis on designing ethnically tailored educational materials to teach Mexican-Americans in order to improve dietary compliance.

\section{Program Evaluation}

Several evaluative studies have documented the beneficial effects of diabetic educational programs for the general population (Bash, Siepcevich, Gold, Duncan \& Coble, 1985; Graber et al., 1977; Lane \& Evans, 1979; Legge et al., 1980). Evaluative research on the efficacy of ethnically modified educational programs is, at present, completely lacking in the literature. Paulozzi et al. (1984), in their evaluation study with Anglo-American diabetic outpatients, suggested that outpatient education offers a significant improvement in diabetes control. Measures that have been suggested to evaluate patient educational programs included: (a) metabolic control, (b) adherence to diabetic regimen, (c) knowledge, (d) skills, (e) behavior, (f) attitudes, (g) use of health services, (h) days missed from work, (i) hospitalization, (j) complications, and (k) costs (Rosenstock, 1985). Kaplan and Davis (1986) pointed out that no single one of these measures in and of itself has been found to be an 
entirely satisfactory method for evaluating diabetes educational programs.

Regardless of the population served, patient diabetes education has two goals: (a) to assist patients to become active subjects in their own care, and (b) to provide patients with the necessary health care skills to prevent complications. Dudley (1989) indicated that education results in new knowledge and understanding, and that health education has as its goal positive behavioral change. He further points out that in evaluating patients' progress, emphasis should be placed on encouraging individuals toward active participation in the goal setting and evaluation process. This emphasis will enable patients to develop feelings of self confidence in their ability to care for themselves, thereby encouraging adherence to an effective treatment regime.

One of the prerequisites of quality diabetes care is that patients must have better knowledge about the disease to be motivated for an active role in its treatment (Rosenqvist, Carlson \& Rolf, 1988). Rosenstock (1985) indicated that the following factors may positively influence patient outcome: (a) teaching sessions including a discussion of treatment benefits, (b) techniques for making changes, (c) specific information about ways to incorporate changes, and (d) potential barriers to successful control. Therapeutic compliance will be enhanced once patients are assisted with proper coping skills and diabetes education is modified to their special needs. 


\section{Summary}

The literature supports all aspects of patient education as a necessary component of nursing care. Patient education and involvement are vital parts of quality health care in a chronic disease such as diabetes. The increase in the Mexican-American population linked to a corresponding increase in diabetes has been a challenge for the American health care system in the United States. This increase has put new demands on health care systems to provide health care that is culturally sensitive to the needs of this population, as well as effective and economical. Mexican-Americans respond more positively to educational and therapeutic efforts that use the Spanish language and are sensitive to Hispanic-American cultural values (U.S. Department of Health and Human Services, 1986). The National Diabetes Advisory Board (1984) has set standards for diabetes patient education. One of the standards of a successful program is a flexible approach based upon the needs of the community that it is intended to serve.

Literature discussing cultural aspects of health indicates that the American health care system is becoming increasingly aware that one of the educational needs is the urgency of incorporating cultural sensitivity into community health educational programs (Andersen et al., 1981; Falk, 1072; Hall, 1987). As part of this awareness, many representatives of the Mexican-American and Anglo-American cultures within the United States have been working together to overcome barriers to communication and 
understanding in an attempt to meet the health education needs of the Mexican-American community. 


\section{Chapter 3}

\section{METHODOLOGY}

Design

This study used a quasi-experimental design to measure the effect of culturally modified classes on health belief affecting selfcare attitudes of Mexican-Americans with type II diabetes.

Lo Biondo-Wood and Haber (1986) define a quasi-experimental design as one in which the researcher initiates an experimental treatment where the design lacks at least one of the 3 properties characteristic of the true experimental design: (a) randomization, (b) manipulation, or (c) control group.

Lo Biondo-Wood et al. (1986) indicated that the soundness of the design and the confidence in the findings of a study depend on the strength of the assumption that the groups to be compared have a high degree of similarity before the test begins. It is important in this type of study to select groups that are demographically similar. In this study the independent variable was a culturally modified education program, and the dependent variable was health beliefs affecting self-care attitudes of Mexican-Americans after attending that program or one which was not culturally modified.

\section{Approval for Human Subjects Study}

The research protocol and instrument were submitted to and reviewed by the Human Subjects Review Board of San Jose State 
University (Appendix A). Letters of consent in English and Spanish (Appendices B \& C) were included explaining how the study addressed specific needs of the Mexican-American population and encouraged better care of their diabetic condition. Risks were identified as minimal, such as distress from concentration while responding to the questionnaire, and were discussed with each subject. The clients were informed that their participation was strictiy voluntary and that they could withdraw or stop at any time without jeopardizing their health care. The research proposal was submitted to and approved by the Education Program Director at the Diabetes Society (Appendix J) and the Site Director, Multi-Purpose Senior Services Program (Appendix K) prior to data collection.

\section{Sample}

Two convenience groups of Mexican-American clients were selected from the Diabetes Society and the Multi-Purpose Senior Services Program (MSSP). The experimental group received culturally modified diabetes classes and the control group did not receive any culturally modified diabetes classes. To increase the study's validity, the control and experimental groups were demographically similar. The following traits were used as criteria to determine participation in both groups: (a) Mexican-American, (b) age 45 and up, (c) type II diabetes diagnosis, (d) low socioeconomic level, (e) MediCal recipients, and (f) informed consent. Selection specifically excluded Hispanic clients with one of the following traits: (a) age 44 or younger, (b) type I diabetes, and 
of the following traits: (a) age 44 or younger, (b) type 1 diabetes, and (c) high educational or socioeconomic level. Low socioeconomic status was determined by using the criteria of the MediCal insurance standards (U.S. Department of Health and Human Services, 1988).

The experimental group for this study consisted of 30 subjects selected from approximately 100 clients of the Diabetes Society register. This group had attended one or more culturally modified classes between January, 1989 and January, 1990. The control group consisted of 30 subjects from the Multi-Purpose Senior Services Program and the Diabetes Society who were invited to the classes, but never attended. This group did not attend the culturally modified classes but received traditional diabetes counseling and/or special diet instruction by their regular health care providers. Both the experimental and control groups were under medical care.

Before administration of the questionnaire, the subjects received details about the nature and purpose of the study. In addition, they received the human subject consent form in English or Spanish (Appendices B \& C). Initial communication was directed at building trust and rapport with the subject in order to enhance confidentiality and minimize negative testing reactivity.

\section{Culturally Modified Diabetes Class}

The culturally modified diabetes classes for MexicanAmericans consisted of an educational program translated to Spanish and culturally adapted using the Anglo-American Diabetes Education Syllabus. The objective of the program was to meet the 
needs of the Mexican-American population on self-care of diabetes through presenting culturally modified material. The material was modified to include words and examples of ideas that were common in their everyday living experiences. The 3 hour class presented the basics of diabetes control, emphasizing self-care through: (a) diet, (b) exercise, (c) foot and skin care, and (d) blood self-testing.

Various health professionals were trained to teach this class by attending special classes that presented culturally modified material on nutrition, with emphasis on the Mexican-American diet, cultural aspects of diabetes issues, and teaching techniques appropriate for the level of the clients. Two bicultural, bilingual health care providers taught each class in specific settings in the community. Each class was taught using the same content and format from the Resource Manual for Diabetes Education Adapted to Hispanics (Diabetes Society of Santa Clara County, 1987). Validity and reliability for class content were tested by having each of the staff members teach the class back to the group. The teaching staff met with the education director every 6 to 8 weeks to discuss diabetes, Hispanic issues, and plans for future classes. Continuing education classes were offered to the staff to stay current on issues related to the program, and ensure consistency in teaching techniques.

In order to reach these Hispanic diabetics, the Diabetes Society sent fiyers announcing the class to hospitals, senior centers, and other health agencies. Further, the health care 
providers at these various health agencies encouraged their Mexican-American clients to attend these classes as an excellent method of gaining knowledge about and learning how to better cope with diabetes.

\section{Setting/Procedure}

The investigator contacted all subjects by telephone, to explain the purpose and significance of the study. This investigator then made arrangements for a home visit with those who agreed to participate in the study. The Diabetes Health Belief Scale questionnaire was administered to each subject in the experimental and control group in their respective home by this investigator, a bilingual, bicultural registered nurse. A large number of the subjects' homes were located in a low socioeconomic urban neighborhood. The majority of home visits to subjects of the study took place on weekends. All of the subjects preferred using their living or dining room to complete the questionnaire. Data collection was completed in 6 weeks. Four subjects were individually interviewed at one of the day health-care centers and 4 subjects at a senior community center. Both sites provided a quiet, private room to satisfy the need for privacy and safety.

\section{Instrument}

The tool used to assess the Mexican-American client's attitudes about diabetes self-care was the Diabetes Health Belief Scale (DHES) (Appendix E) (Harris, Linn, Skyler \& Sandifer, 1985). Permission to use this tool was given by Dr. Linn, one of the authors 
colleagues to measure health beliefs to help specify the types of intervention for diabetic patients that might improve compliance. Items on the DHBS are rated on a 4 point Likert scale, "1" indicating no agreement at all with the statement and "4" indicating high agreement with the statement.

The items of the DHBS were originally generated from the theoretical literature of the HBM and previously used scales to measure health beliefs (Becker et al., 1977; Rosenstock, 1974). A preliminary version of the scale contained 71 items covering areas identified as important in determining health behavior. Several steps were taken into consideration by the tool developers to test validity and reliability of the DHBS. Reliable items and those that had considerable variance or the potential for discrimination between groups were selected from the original 71 items. Forty items were selected and submitted to factor analysis and seven relatively independent and reliable concepts or subconcepts were chosen that corresponded to the seven dimensions of the health belief model. The subconcepts and proportion of variance they accounted for were: (a) general health motivation (4.3\%), (b) treatment benefit $(7.3 \%)$, (c) severity $(6.7 \%)$, (d) susceptibility $(8.6 \%)$, (e) psychological barriers $(5.5 \%)$, (f) cues to action $(6.5 \%)$, and $(\mathrm{g})$ structural elements $(5.5 \%)$.

Validity of the scale was tested with a convenience sample of 280 male patients from a diabetes clinic. Adherence was measured 
by self-report and nurse's evaluation as well as by metabolic indicators from laboratory tests including: (a) 24-hour urine, (b) fasting blood sugar, (c) fasting triglyceride, and (d) glycosylated hemoglobin level. Reliabilities and intercorrelations of the tool were tested using a randomly selected sample of 30 male diabetic patients from the original population of 280 male diabetic patients. Test-retest scores in the intraclass correlations ranged from .40 to .83 for the DHBS. Harris et al. (1985) pointed out that although the above correlations are statistically significant, the correlation of .40 reflect only minimal reliability in the small sample studied. Further, the researchers (Harris et al., 1985) indicated that the intraclass correlation is a more stringent test of reliability than are other types of correlation because it takes into account the direction of ratings as well as distance between ratings.

The English questionnaire (Appendix E) was translated into Spanish (Appendix G) by this investigator for simplicity of administration since the majority of the subjects could neither speak nor read English. The Spanish translation was validated as accurate according to content by an expert from the Department of Foreign Languages at San Jose State University (Appendix F). The Spanish version of the questionnaire was requested or preferred by 58 subjects; only 2 subjects requested the English version.

Questions were read by the investigator to each subject in order to prevent misunderstanding due to the varied reading ability of the subjects. The subjects' answers were recorded on the questionnaire. 
Questions were either repeated or explained when requested by a subject.

The DHBS was developed to be used with the Anglo-American population (Harris et al., 1985). It was translated into Spanish in order to use it with the 2 samples of Mexican-American diabetics. Cronbach alpha coefficients were calculated for each of the seven subscales to obtain information on the internal validity of the DHBS when used with the Mexican-American sample in this study (Table 1). Six of the 7 DHBS subscales reflected moderate to high reliability coefficients ranging from .54 to .77 . The Psychological Barriers subscale reported a low reliability coefficient of .30. Findings of the Cronbach alpha reliability coefficients indicated that with translation of the instrument into Spanish the DHBS appeared to retain its reliability.

\section{Data Collection}

Subjects' demographic and medical data were collected regarding the following variables: (a) age, (b) sex, (c) education, (d) diabetic regimen, (e) duration of diabetes, $(f)$ diabetes complications, (g) family history, and (h) number of classes attended. The usual length of the data collection visit was 30 minutes, although a few of the subjects took up to 45 minutes to complete the visit. To maintain strict confidentiality, a name was not assigned to any questionnaire and all data were analyzed anonymously. In order to make home visits, a list with the subjects' 
Table 1

Factor Reliability Coefficients Cronbach Alpha of the Spanish Version of the DHBS

General Health Motivation

Treatment Benefit

Severity .65

Susceptibility .74

Psychological Barriers .30

Cues to Action .54

Structural Elements

name, address, and telephone number was used. This list was kept in the investigator's files and destroyed after the visits.

\section{Analytical Procedures}

The data were analyzed using the Statistical Package for the Social Sciences (SPSS) program of descriptive statistics (The California State University, 1982). A t-test was performed to determine the differences between the two sample groups' health beliefs affecting self-care attitudes about their disease, treatment, and compliance. The t-test is a parametric statistical test that examines the difference between the means of two groups of values (Polit \& Hungler, 1985). The analysis was based upon results of the 
7 subscales of the DHBS scores (Appendix $H$ ). There is no total score for the DHBS.

Results were organized into tables showing statistical differences between the experimental and control group. The mean scores of the 7 concepts of the DHBS were compared between the experimental and control groups to evaluate the effects of culturally modified diabetes education classes on the Mexican-American health beliefs affecting self-care attitudes. The procedures used in implementing the data collection of this study fulfilled the criteria for the quasi-experimental design. 


\section{Chapter 4}

\section{FINDINGS AND INTERPRETATIONS}

This chapter presents the analysis of the findings from the study. The purpose of the analysis was to support or reject the research question: Is there a difference in health beliefs affecting self-care attitudes towards diabetes control between MexicanAmericans who attended a culturally modified diabetes class and those who did not attend the class? Selected demographic variables of both groups were described. The means and standard deviations for each of the 7 subscales of the DHBS on the experimental and control group are discussed.

Demographic Variables

Demographic characteristics were examined and analyzed to compare and establish similarities between the control and experimental group since a random selection of the sample was not possible (Appendix 1). These characteristics were useful in comparing differences or consistencies in the interpretation of the health belief factors in this study. Means, standard deviations, and ranges of demographic variables are shown in Table 2.

The number of classes attended by the experimental group indicated a mean of 2.7 with a range of 1 to 7 classes. Twenty subjects in the experimental group were females and 10 were males. Subjects in the control group included 25 females and 5 males. This 


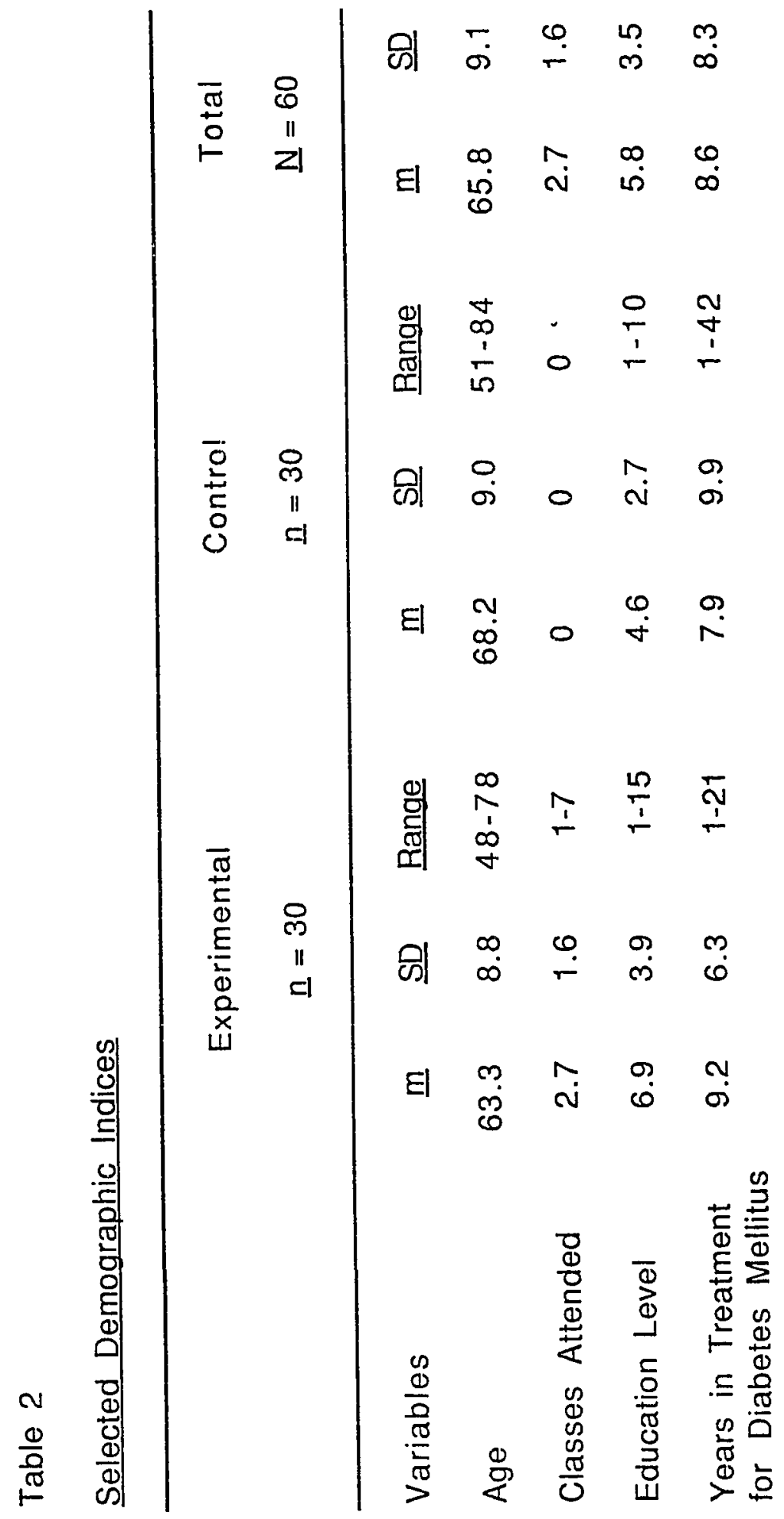


study included a low number of male subjects because those contacted would not agree to participate. Further, 4 subjects that said they would participate failed to be home for the appointed visit. These 4 male subjects declined to participate when a second home visit was attempted. Some of the other male subjects were helped by their spouses to answer the questionnaires. In the experimental group, most of the wives or a female relative reported that they also attended the class in order to assist the male diabetic to better manage the disease. The mean age for the experimental group was 63.3 years with a range of 48 to 78 years, while the control group's mean age was 68.2 years with a range of 51 to 84 years. Educational level means were 6.9 for the experimental group and 4.6 for the control group with a range of 1 to 15 and 1 to 10 years in school respectively. One of the females in the experimental group reported a college education with a bachelor's degree in social work. The higher education of this subject accounted for the increase of the educational level mean in this sample. The mean average since the diagnosis of diabetes for the experimental group was 9.2 years with a range of 2 to 21 years and the mean for the control group was 7.9 years with a range of 1 to 42 years.

Nine of the subjects in the experimental group and 10 of the subjects in the control group used insulin to control diabetes. Nineteen of the subjects in each group used oral hypoglycemic agents, and 2 subjects, 1 in each group, managed diabetes by diet alone. Subjects in both groups reported one or more relatives as 
having diabetes (Table 3). The breakdown of the sample by subjects was as follows: The experimental group reported 35 relatives as having diabetes, of these 27 were females and 8 were males. Eleven subjects in the experimental group did not know of a history of diabetes in the family. The control group reported 32 relatives as having diabetes, of these 21 were females and 11 were males. Fourteen subjects in the control group did not know of a history of diabetes in the family. This finding is consistent with past documented research which indicates a higher prevalence of diabetes among Mexican-American females (Stern, Rosenthal, Haffner, Hazuda \& Franco, 1984).

One or more complications or symptoms were reported by the majority of both groups (Table 4). The mean number of symptoms for the experimental group was 4.1 and for the control group was 3.5. Complications or symptoms reported by subjects in the experimental group were as follows: eye problems (13), total blindness (1), hypertension (10), neuropathy (numbness) (10), circulatory problems (7), skin ulcerations (5), heart problems (4), kidney problems (1), bladder infections (1), and amputation of 3 toes (1). Two of the subjects in the experimental group denied having any complications. In comparison complications or symptoms reported by subjects in the control group included: eye problems (12), partial blindness (1), hypertension (10), neuropathy (numbness) (9), circulatory problems (9), skin ulcerations (3), kidney problems (1), recurrent bladder infections (1), and amputation of a leg (1). 
Table 3

Summary of Diabetes Family History: Frequency of Diabetes in the Families of the Experimental, Control, and Combined Samples

\begin{tabular}{lccc}
\hline Diabetes Family History & $\begin{array}{c}\text { Experimental } \\
(\underline{\mathrm{n}}=30)\end{array}$ & $\begin{array}{c}\text { Control } \\
(\underline{\mathrm{n}}=30)\end{array}$ & $\begin{array}{r}\text { Total } \\
(\underline{\mathrm{N}}=60)\end{array}$ \\
\hline Grandmother & 2 & 0 & 2 \\
Grandfather & 0 & 0 & 0 \\
Mother & 9 & 9 & 18 \\
Father & 3 & 4 & 7 \\
Sister & 9 & 9 & 18 \\
Brother & 1 & 2 & 3 \\
Daughter & 6 & 3 & 9 \\
Son & 3 & 5 & 8 \\
Aunt & 1 & 0 & 1 \\
Nephew & 1 & 0 & 1 \\
\hline
\end{tabular}


Table 4

Summary of Diabetes Complications and/or Symptoms.

Frequencies, within the Experimental. Control, and Combined

Samples.

\begin{tabular}{lccc}
\hline Diabetic Complications & $\begin{array}{c}\text { Experimental } \\
(\underline{n}=30)\end{array}$ & $\begin{array}{c}\text { Control } \\
(\underline{n}=30)\end{array}$ & $\begin{array}{r}\text { Total } \\
(\underline{N}=60)\end{array}$ \\
\hline Eye Problems & 13 & 12 & 25 \\
Total Blindness & 1 & 0 & 1 \\
Partial Blindness & 0 & 1 & 1 \\
Hypertension & 10 & 10 & 20 \\
Neuropathy (numbness) & 10 & 9 & 19 \\
Circulation Problems & 7 & 9 & 16 \\
Skin Ulcerations & 5 & 3 & 8 \\
Heart Problems & 4 & 0 & 4 \\
Kidney Problems & 1 & 1 & 2 \\
Bladder Infections & 1 & 1 & 2 \\
Amputation of Toes & 1 & 0 & 1 \\
Amputation of Leg & 0 & 1 & 1 \\
\hline
\end{tabular}


Six of the subjects in the control group denied having any complications. Eye problems were the complication most mentioned by subjects, with one blind female subject in the experimental group and one partially blind female in the control group. Two subjects in the experimental group reported having had heart bypass surgery.

The means of the demographic variables for the 2 samples, the experimental group attending the culturally adapted classes, and the control group not attending the culturally adapted classes, indicated that the groups had similar characteristics. This finding suggests that demographic data identified in each group did not contribute to any statistical error or bias.

Diabetes Health Beliefs Findings and Interpretations

The analysis of the study was based upon the results of the Diabetes Health Belief Scale (DHBS) questionnaire administered to the two samples of adult Mexican-Americans with type II diabetes. Sixty subjects answered and completed the questionnaire. The answers on the 37 items on the questionnaire were analyzed using the factors of the DHBS (Appendix $H$ ), consisting of 7 variables of the Health Belief Model (HBM). The following paragraphs discuss scores for each of the seven subscales of the DHBS, relating findings of specific interests for both groups (Table 5). Reliability of the Spanish version of the DHBS used in this study was established by using the Cronbach Alpha Coefficients.

Findings Related to General Health Motivation

The General Health Motivation factor (Factor 1) consists of 


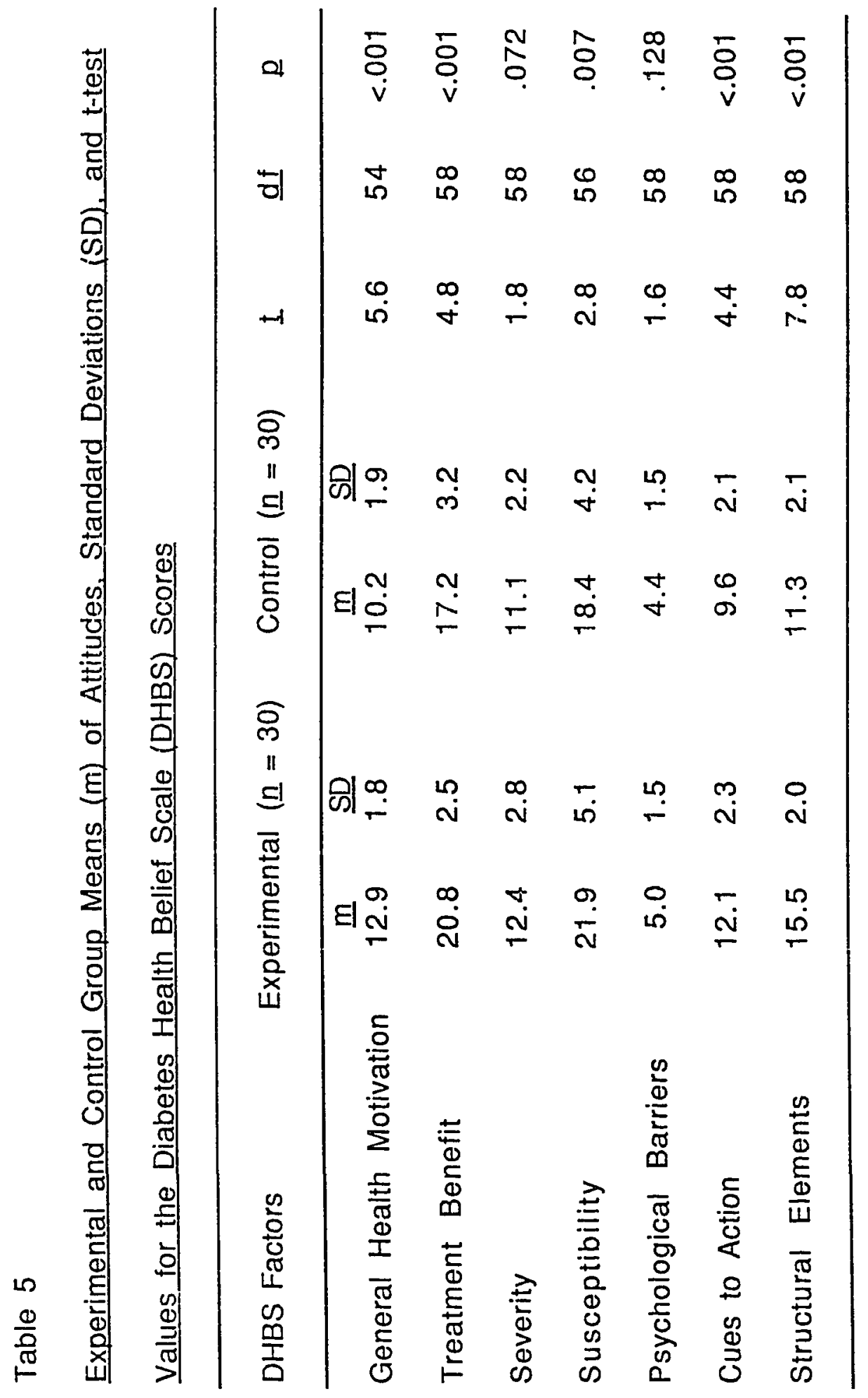


5 items concerning general health. These items were scored using a 4 point Likert scale, "1" indicating no agreement at all with the statement and "4" indicating high agreement with the statement. The item related to taking their temperature when sick as a health incentive scored very low in both groups with a mean of 1.4 for the experimental group and 1.1 for the control group. Most of the subjects stated they did not know how to read the thermometer, and very few had a thermometer in the house. This inability to read a thermometer may be indicative of their lack of health education to attain this knowledge or it may indicate that they do not consider temperature taking to be important. However, item 2, related to seeking medical examinations even when feeling healthy, scored higher as a health motivational factor with a mean of 3.3 in the experimental group and 2.9 in the control group. The item related to weight, an important part of self-management of diabetes, scored very low in both groups with a mean of 2.0 for the experimental group and 1.2 for the control group.

Items related to diet as a health incentive had a significant difference in the answers. Both groups scored high on the item asking, "how much do you worry about what you eat," with a mean of 3.2 in the experimental group and 2.9 in the control group. However, when the same subjects were asked, "how much are you able to stay on your diet," the mean decreased to 2.6 for the experimental group and 2.0 for the control group. Subjects in both samples commented on knowing the importance of the diabetic diet but stated they have 
problems adhering to the regimen, many indicating that the diet interfered with having a satisfactory life style. This statement indicates that both groups knew about diet as an important element of the diabetes regime and they were concerned about it, although their concern did not influence their behavior. These findings are consistent with previous studies which indicate that diet adherence is the most difficult behavior for type II diabetics (Ary et al., 1986; Rosenstock, 1985). These findings suggest that for the MexicanAmerican groups in this study certain health measures, such as seeking medical examinations even when feeling healthy, were perceived as good health practices. However, other health practices such as, temperature taking, weight monitoring, and diet control were not perceived as health motivation factors. There was a significant difference $(\mathrm{I}(54)=5.6, \mathrm{p}<.001$ ) (Table 5 ) in the health beliefs for general health motivation between the 2 groups.

Findings Related to Treatment Benefit

The Treatment Benefit factor (Factor 2) consists of 6 items and is concerned with the belief that the recommended action or intervention of the physician will result in a reduction of the health threat. These items were scored using a 4 point Likert scale, "1" indicating no agreement at all with the statement and " 4 " indicating high agreement with the statement. Physician intervention to achieve a longer life span was rated high for both samples with a mean of 3.6 for the experimental group and 3.1 for the control group. Having problems with not taking medication reported means of 3.3 
for the experimental group and 3.1 for the control group. The item related to keeping clinical appointments reported means of 3.7 for the experimental group and 3.1 for the control group. Physician intervention with kidney disease reported means of 2.6 for the experimental group and 2.3 for the control group. Physician intervention with tingling and numbness symptoms (neuropathy) of the extremities reported means of 3.1 for the experimental group and 2.3 for the control group. Mean scores for the tendency to seek medical treatment in order to reduce chances of developing diabetic complications were 3.8 for the experimental group and 2.9 for the control group. Having problems with not taking medication, keeping regular clinic appointments, and seeking medical treatment in order to reduce chances of developing diabetic complications were perceived as important health actions in reducing the health threat. Physician intervention to achieve a longer life span was perceived as more important in reducing the health threat than physician intervention for specific symptoms such as, kidney disease and numbness symptoms (neuropathy). Treatment Benefit was a significant factor reported ( $\mathrm{t}(58)=4.8, \underline{\mathrm{p}}<.001$ ) (Table 5).

Findings Related to Severity

Severity (Factor 3 ) consisted of 5 items and measured the individual's perception of the seriousness of the illness and its impact on the individual's life. These items were scored using a 4 point Likert scale, "1" indicating no agreement at all with the statement and "4" indicating high agreement with the statement. 
The item related to kidney disease interfering with normal everyday activities reported means of 2.1 for the experimental group and 1.3 for the control group. Skin problems interfering with everyday activities reported means of 1.2 for the experimental group and 1.0 for the control group. The scores for the items related to an amputation interfering with everyday activities were equal in both groups with means of 3.1. Eye disease interfering with daily activities were closely matched with means of 3.1 for the experimental group and 3.2 for the control group. Numbness and tingling symptoms (neuropathy) interfering with everyday activities reported close scores for both groups with means of 2.6 for the experimental group and 2.5 for the control group.

Amputation, eye disease, and numbness and tingling were perceived as a high threat to lifestyle, while kidney disease or related symptoms and skin problems were rated low as a threat of perceived severity in both groups. Only 1 subject in each group reported kidney disease. Feelings concerning the seriousness of an amputation was perceived by both groups as a threat related to the severity factor of the DHBS, although neither group reported symptoms related to this problem. Poor circulation, eye disease, and neuropathy symptoms had higher means indicating perception as a threat also by both groups, and these complications and symptoms were reported in both groups. The above findings indicated that perception of the seriousness of the illness and its impact on the individual's life was determined by the seriousness of the symptoms 
experienced by subjects in this study. Statistical findings on this scale indicated a nonsignificant difference between the two groups $(t(58)=1.8, \underline{p}=.072)$ (Table 5).

Findings Related to Susceptibility

Susceptibility (Factor 4) consists of 10 items. This factor measured the threat of becoming sick from diabetes, developing complications, or having complications of the disease become worse. These items were scored using a 4 point Likert scale, "1" indicating no agreement at all with the statement and "4" indicating high agreement with the statement. In measuring susceptibility, the samples matched equally in their belief of diabetes to be a threat in causing a shortened life expectancy with a mean of 2.5 for both samples. The item, "getting sick easily," was rated low for both groups with means of 1.9 for the experimental group and 1.8 for the control group. The item, "concern about getting sick," was rated higher with means of 2.8 for the experimental group and 2.5 for the control group. Six of the items on this scale were related to developing complications or having complications of the disease become worse. Poor circulation problems rated equally with a mean of 2.6 for both groups. Amputation problems reported means of 2.0 for the experimental group and 1.4 for the control group. The mean for kidney disease and skin problems was rated low for both groups, 1.8 for the experimental group and 1.1 for the control group. Skin problems reported means of 1.9 for the experimental group and 1.0 for the control group. The mean scores for numbness and tingling at 
the extremities were 3.1 for the experimental group and 2.8 for the control group. The means for eye disease were 2.9 for the experimental group and 2.6 for the control group.

Items related to symptoms or complications experienced by the subjects in both groups reported higher means than the items related to the symptoms not experienced by the groups. This finding related to symptoms was observed to be an occurrence in all the subscales that had symptom or complication related questions. The results are consistent with past studies which indicated that the Mexican-American client requires the presence of symptoms to diagnose illness (Quesada, 1976). Therefore, symptoms that are not experienced are not considered a threat (perceived susceptibility). Item 34 related to impotence was omitted during the study statistical analysis process. This item addressed only the male population (25\% of the combined sample), resulting in omissions by $75 \%$ of the sample who were female. The high percentage of omissions would have skewed the results for this factor. Therefore, it was decided to omit the item related to impotence to allow a viable statistical comparison of the susceptibility subscale. Analysis of the susceptibility subscale showed statistical significance ( $\mathrm{t}(56)=2.8, \underline{\mathrm{p}}=.007$ ) (Table 5).

Findings Related to Psychological Barriers

The Psychological Barriers subscale includes 3 items (Factor 5) which need to be overcome for the person to follow medical advice. This factor is usually referred to as the "perceived cost" 
involved in following the prescribed treatment. The items in this factor are concerned with diet and medication interfering with everyday activities of living and hesitating to tell new friends about having diabetes. These items were scored using a 4 point Likert scale, "1" indicating no agreement at all with the statement and "4." indicating high agreement with the statement. The mean scores for diet and medication interfering with everyday activities of living and hesitating to tell new friends about having diabetes were very low for both groups. The analysis of the data found no statistically significant effects ( $t(58)=1.6, \underline{p}=.128$ ) with the above psychological barriers (Table 5). This finding suggests that these aspects of the diabetes regimen were not perceived as barriers impeding their daily life style.

\section{Findings Related to Cues to Action}

Cues to Action (Factor 6) consists of 4 items, and it assessed the symptoms that would be likely to lead to the seeking of medical intervention. All 4 items were designed to determine the relationship between experiencing specific symptoms and the willingness to seek medical help. These items were scored using a 4 point Likert scale, "1" indicating no agreement at all with the statement and "4" indicating high agreement with the statement. The symptoms were cold sweats, shortness of breath, vomiting and having a problem with concentration. In response to cold sweats means for the experimental group were reported as 2.6 and for the control group were 3.0. In response to vomiting, means for the 
experimental group were reported at 3.3, and for the control group were 2.1. Concentration problems showed a mean of 2.8 for the experimental group and 1.4 for the control group. The group attending the classes were taught the importance of recognizing these symptoms and other symptoms related to hypoglycemia and hyperglycemia and what action to take if these symptoms are experienced. Subjects in the experimental group perceived these symptoms to be more serious than the control group. The item related to shortness of breath was perceived as a cue to action by both groups demonstrated by the mean of 3.3 for the experimental group and 3.0 for the control group. However, the majority of the subjects in both groups related this symptom to "life itself" and not necessarily as a symptom of diabetes. Cues to action showed a significant statistical difference $(\mathrm{t}(58)=4.4, \mathrm{p}<.001)$ (Table 5).

Findings Related to Structural Elements Structural Elements (Factor 7) consists of 5 items which assessed the patient's understanding of and family support for the treatment regimen. The means of the experimental group were higher on items related to family support when compared to the control group. These items were scored using a 4 point Likert scale, "1" indicating no agreement at all with the statement and "4" indicating high agreement with the statement. The items related to family and close friends helping clients to stay on their diet reported means of 3.0 for the experimental group and 2.2 for the 
control group. The items for how often separate meals were prepared for the client reported means of 2.6 for the experimental group and 1.4 for the control group. These findings indicated that friends, especially family support, were an important factor to consider in motivating a positive attitude towards treatment compliance of the Mexican-American diabetic client. The itern that asked about helpfulness of an education program for diabetic patients showed a higher mean for both groups, 3.9 for the experimental group and 3.1 for the control group. However, the item related to understanding the treatment for diabetes showed means that were lower: 2.8 for the experimental group and 1.7 for the control group.

Subjects who attended two or more culturally modified classes understood their diabetes treatment more clearly, scoring 3 's and 4's on the scale of understanding their diabetes treatment. The control group reported lower understanding of their diabetes treatment. Both groups reported being under medical care and having received either the culturally modified classes or traditional diabetes related counseling or education. However, the low score for the control group in understanding their diabetes treatment suggest that the strategies that were used with this group to transmit information about diabetes treatment were not successful. This finding suggests that the Mexican-American client needs a diabetes education program to which they can relate and understand. 
Structural elements showed a significant statistical difference $(\mathrm{t}(58)=7.8, \mathrm{p}<.001)$ (Table 5).

\section{Summary}

The DHBS was used to measure health beliefs affecting selfcare attitudes of the Mexican-American client. The t-test indicated a statistically significant difference $(p<.05)$ in 5 of the 7 DHBS subscales (Table 5). The findings suggest that a culturally modified diabetes education program may significantly improve healt' beliefs affecting self-care attitudes.

The Structural Elements factor was the DHBS subscale with the greatest significant score. This scale measured the understanding of the diabetes treatment and the presence of family support for the treatment regimen. Results showed that support by the family unit is important for the Mexican-American client who has diabetes. The higher scores for the experimental group on understanding diabetes treatment suggested that culturally sensitive patient education is a successful education strategy in motivating the Mexican-American client to change health beliefs affecting self-care attitudes.

The Susceptibility factor was the DHBS subscale with the lowest significant scores. This subscale indicated perception of personal vulnerability to diabetes and its complications as a threat by the experimental group. The threat of having their diabetes become worse through complications served as motivation for this group to practice positive self-care attitudes. 
The Health Motivation subscale was the most complex to analyze because of the different health practices presented. For instance, when clients were questioned about items related to diet and weight they acknowledged understanding the importance of these health practices as part of the diabetes management but reported having difficulty in maintaining a controlled diet and weight. The avoidance of temperature taking was reported by clients because of their apparent lack of knowledge on how to use a thermometer. The sample may have been aware of what health practices to follow but because of their lifestyle did not always choose the optimum health practices. The Treatment Benefit subscale findings indicated that the Mexican-American clients' acceptance of preventive health recommendations such as physician intervention, clinic visits, and medical treatment were perceived as being important health practices by both samples. Since both samples were under medical care they may have been aware of the positive effects of these health interventions to control their condition. In measuring the seriousness of symptoms that would likely cause the patient to seek medical intervention, specific symptoms such as cold sweats, shortness of breath, and vomiting were perceived by the Mexican-American client as important cues to seek medical intervention.

Two of the DHBS's revealed non statistical differences between the 2 groups. Findings of the severity factor indicated that seriousness of the disease was not perceived by either group as 
interfering with their everyday activities. Findings of the Psychological Barriers factor showed that for the samples tested, aspects of diabetes regimen such as diet and medication interfering with everyday activities were not perceived as barriers impeding their daily life style.

While the HBM itself suggests no particular strategy for altering beliefs, the effect of culturally modified classes tested in this study was found to have significant effect on health beliefs of the Mexican-American through improved self-care attitudes. Since the only real difference between the 2 groups was the type of diabetes education received, it appears that this course adapted for the Hispanic population was beneficial in assisting diabetic clients in promoting optimum self-care to live with diabetes. 


\section{Chapter 5 \\ DISCUSSION \\ Summary of Study}

This evaluative study was designed in part to determine the effect of a culturally modified diabetes education program on the health beliefs affecting self-care attitudes of the MexicanAmerican client. Diabetes is a serious chronic disease of national concern, disproportionately affecting some minority groups in the United States including Mexican-Americans, the group identified in this study. According to Bonheim (1985) the estimated figure of the total cost of diabetes in 1984 was almost $\$ 14$ billion. A large share of this cost is borne by the 4 minority groups hardest hit by the disease: Native-Americans, Hispanic-Americans, Blacks, and Asians (U.S. Department of Health and Human Services, 1986). A large proportion of the cost of diabetes could be saved with more effective diabetes education programs based upon the needs of the population to be served.

This study emphasized the higher incidence, prevalence, and complication factors of diabetes among Mexican-Americans. Different factors that have influenced the lack of access to medical services by this population were mentioned. Although several studies on diabetes related educational programs are presented in the literature, development, implementation, or evaluation of 
culturally modified educational programs for Mexican-Americans at the present time are either extremely limited or completely lacking in the literature.

In applying the HBM, Becker and Janz (1984) stated that by determining which model elements are below a level presumed necessary for attaining adherence to treatment, the health care provider should be able to tailor interventions to suit the particular needs of each patient. They further suggested that the HBM provides the framework in which the diabetes educator can make an "educational diagnosis," making efforts to improve the diabetic patient's adherence to recommendations by focusing their attention upon relevant identified attitudes and beliefs. Nurses working with the Mexican-American client need to consider: (a) cultural factors of health related behavior, (b) knowledge and understanding of the cultural values, and (c) health beliefs of the ethnically different client. The nurse can then direct more culturally significant efforts towards helping this group develop positive self-care attitudes for effective diabetes management. Culturally modified diabetes educational programs will not answer all of the needs of the problem of diabetes among Mexican-Americans, but this study demonstrated that these culturally modified classes were capable of increasing positive self-care attitudes among the sample studied.

Conclusions

This study has demonstrated that culturally modified education can have a very positive effect on the Mexican-American 
client self-care attitudes affecting health behaviors. The conclusion drawn by these findings indicates that health education works better if it is appropriately adapted to the health problem and the needs of the population for which it was implemented. The results of this study suggest that intervention through culturally modified education is an effective strategy to motivate culturally different populations to improve health beliefs affecting self-care attitudes.

\section{Scope and Limitations}

The scope of this study was to obtain data from the Diabetes Health Belief Scale (DHBS) after it was administered to the two samples participating in this study. This study had some limitations primarily due to the quasi-experimental design. In using a nonexperimental design, variables were not manipulated and some intervening variables were not controlled, thus a clear cause and effect relationship was not determined. The 2 samples used in this investigation were made up of a homogeneous group: (a) age 45 and above, (b) low socioeconomic and educational level, and (c) type II diabetic, Mexican-Americans. Therefore, generalizations to a larger diabetic population are limited. Groups were selected in order to be as homogeneous as possible in regards to demographic variables to preclude confounding variables affecting the outcomes. The improvement on self-care attitudes indicated in the results must be considered in light of this study's limitations. 
Recommendations for Further Study

Based on observations and findings from this study, the following recommendations are proposed:

1. Future research is needed on development, implementation, and evaluation of health educational programs relevant to the MexicanAmerican population.

2. Future studies are needed to explore relationships more precisely between selected demographics and their effects on scores.

3. Replication of this study should be done using different measures such as metabolic control, cost, and improvement in health status to evaluate the social and economic impact of culturally modified diabetes patient educational programs for Mexican-Americans. 4. New tools should be developed which are appropriate for the target population, taking into consideration cultural aspects, age, and educational level.

5. Further study into the cultural factor of the Health Belief Model should be pursued to adapt the model for use with people of different cultural backgrounds.

Recommendations Related to Nursing

The findings of this study have the following implications for nursing and health-care:

1. Preventive diabetes education should start during early childhood. Since there is a familial genetic predisposition to diabetes, clients and their families should be persuaded to seek professional health screening before symptoms appear. Written diabetes information 
given to the client should be family oriented, emphasizing early screening of family members, motivating the client to read the information and to give it to their relatives.

2. Nurses working with Mexican-Americans need to provide information regarding the benefits of various preventive health actions. Clients need to be educated to influence them in continuing a treatment regimen and maintaining medical follow up even if they are without symptoms or lack relief from existing symptoms.

3. Supplemental educational programs on diabetes, such as skin and foot care, exercises, diet, and stress management, should be offered by the agencies involved with the Mexican-American population.

4. Community education on diabetes which increases improvements in self-care attitudes associated with cultural norms should be promoted and made available to all populations.

Since education to promote self-care is recognized to be a fundamental component of quality treatment for the individual with diabetes, competent transcultural teaching by the health educator and nurse motivates the diabetic client to improve health beliefs affecting self-care attitudes. With these improved attitudes, there is a greater chance of preventing complications, thereby enhancing the health status and quality of life for diabetic clients of different cultural backgrounds and their families. 


\section{REFERENCES}




\section{References}

Andersen, R., Zelman-Lewis, S., Giachello, A. L., Aday, L. A., \& Chiu, G. (1981). Access to medical care among the Hispanic population of the Southwestern United States. Journal of Health and Social Behavior, 22, 78-89.

Alogna, M. (1980). Perception of severity of disease and health focus of control in compliant and noncompliant diabetic patients. Diabetes Care, 3 , 533-534.

Anthony-Tkach, K. (1986). Care of the Mexican-American patient. In B. W. Spradley (Ed.), Readings in Community Health Nursing (pp. 425-443). Boston: Little, Brown.

Ary, D.V., Toobert, D., Wilson, W., \& Glasgow R. (1986). Patient perspective on factors contributing to nonadherence to diabetes regimen. Diabetes Care, $\underline{9}, 168-172$.

Barlett, E. E. (1983). Behavioral diagnosis: A practical approach to patient education. Patient Counseling and Health Education, 4 (1), 29-35.

Bash, C. E., Siepcevich, E. M., Gold, R. S., Duncan, D. F., \& Kolbe, L. J. (1985). Avoiding type III errors in health education programs: A case study. Health Educator Quarterly, 12, 315-318.

Becker, M. H., \& Janz, N.K. (1985). The Health Belief Model applied to understanding diabetes regimen compliance. The Diabetes Educator, Spring, 41-47. 
Becker, M. H., Maiman, L. A., Kirscht, J. P., Haefner, D. P., \& Drachman, R. H. (1977). The Health Belief Model and prediction of dietary compliance: A field experiment. Journal of Health and Social Behavior, 18, 348-366.

Becker, M. H., \& Maiman, L. A. (1975). "Sociobehavioral determinants of compliance with health and medical care recommendations" Medical Care, 13, 10-24.

Becker, M. H., Drachman, R. H., \& Kirscht, J. P. (1974). A new approach to explaining sick role behavior in low-income populations. American Journal of Public Health, 64, 204-216.

Bloom-Cerkoney, K. A., \& Hart, L. K. (1980). The relationship between the Health Belief Model and compliance of persons with diabetes Mellitus. Diabetes Care, $\underline{3}, 594-598$.

Bullough, V. L., \& Bullough, B. (1982). Health care for the other Americans. New York: Appleton-Century-Crofts.

Burma, J. H. (1970). Mexican-Americans in the United States. Cambridge, Massachusetts: Schenkman Publishing Company, Inc.

Diabetes Society of Santa Clara County (1987). Resource Manual for Diabetes Education Adapted to Hispanics. San Jose, CA.

Diehl, A. K., \& Stern, M. P. (1989). Special health problems of Mexican-Americans: Obesity, gallbladder disease, diabetes mellitus. and cardiovascular disease. Advanced Internal Medicine, 34, 73-96. 
Dudley, J. (1989). Health education and perceived patient needs. Diabetes Educator, 15 154-155.

Etzwiler, D. D., \& Robb, J. R. (1972). Evaluation of programed education among juvenile diabetics and their families. Diabetes, 21, 967-971.

Falk, V. (1972). Planning health education for a minority group: the Mexican-Americans. International Journal of Health Education, 22, 113-121.

Gaertsen, R., Klauber, M. R., Rindflesh, M., Kane, R. L., \& Gray, R. (1975). "A re-examination of Suchman's views on social factors in health care utilization." Journal of Health \& Social Behavior, 16, 226-237.

Gillum, R. F., \& Barsky, A. J. (1974). Diagnosis and management of patient noncompliance. JAMA, 228, 1563-1567.

Gohdes, D. (1988). Diet therapy for minority patients with diabetes. Diabetes Care, 2., 189-191.

Graber, A. L., Christman, B. G., Alogna, M. T., \& Davidson, J. K. (1977). Evaluation of diabetes patient-education programs. Diabetes, 26, 61-63.

Green, L. W., Lewis, F. M., \& Levine, D. M. (1980). Balancing statistical data and clinician judgments in the diagnosis of patient educational needs. Journal of Community Health, $\underline{6}$, 79-91. 
Haffner, S. M., Rosenthal, M., Hazuda, H. P., Stern, M. P., \& Franco, L. J. (1984). Evaluation of three potential screening tests for diabetes mellitus in a biethnic population. Diabetes Care, $\underline{Z}$, 347-353.

Haffner, S. M., Fong, D., Stern, M. P., Pugh, J. A., Hazuda, H. P., Patterson, J. K., Van Heuven, W. A. J., \& Klein, R. (1988). Diabetic retinopathy in Mexican-Americans and Non-Hispanic Whites. Diabetes, 37, 878-884.

Hall, T. A. (1987). Designing culturally relevant educational materials for Mexican-American clients. The Diabetes. Educator., 13, 281-285.

Harris, R., Linn, M. W., Skyler, J. S., \& Sandifer, R. (1985).

Development of the diabetes health belief scale. The Diabetes Educator, 13, 292-297.

Harwood, A. (1981). Ethnicity and medical care. Cambridge, MA: Harvard University Press.

House Committee on Aging. U. S. Congress. (1989). Hispanic elderly: American's failure to care (Comm. Publications No. 101-735). Washington, DC: U. S. Government Printing Office.

Kaplan, R. M., \& Davis, W. K. (1986). Evaluating the costs and benefits of outpatient diabetes education and nutrition counseling Diabetes Care, $\underline{9}$, 81-86.

Kasl, S. V. (1974). The health belief model and behavior related to chronic illness. Health Education Monographs, 2, 433-454. 
Kirscht, J. P. (1974). The health belief model and illness behavior. Health Education Monographs, 2, 387-408.

Lane, D. S., \& Evans, D. (1979). Measures and methods in evaluating patient education programs for chronic illness. Medical Care, 17. $30-42$.

Legge, J. S., Massey, V. M., Vena, C. I., \& Reilly, B. J. (1980). Evaluating patient education: A case study of a diabetes program. Health Education Quarterly, Z, 148-158.

Leichter, S. B. (1979). Diabetes patient education in hospital settings. The Diabetes Educator, 12, 277-279.

Leininger, M. (1989). The transcultural nurse specialist: Imperative in today's world. Nursing \& Health Care, 10 (5), 251-256.

LoBiondo-Wood, G., \& Haber, J. (1986). Nursing research. St. Louis: Mosby.

Lytt, I., Gardner, L. I., Stern, M. P., Haffner, S.M., Gaskill, S.P., Hazuda, H. J., \& Relethford, J. H. (1984). Prevalence of diabetes in Mexican-Americans: Relationship to percent of gene pool derived from native american sources. Diabetes, 33, 86-91.

Maras, M. L., \& Adolphi, C. L. (1985). Ethnic tailoring improves dietary compliance. The Diabetes Educator, Winter, 47-50.

Mueller, W. H., Joos, S., Ferrell, R., Zavaleta, A., Eichner, J., \& Schule, W. J. (1983). Upper body fat patterning associated with type II diabetes in Mexican-Americans. Diabetes, 32, 420-444. 
National Diabetes Advisory Board (1984). National Standards for diabetes education programs. Diabetes Care, Z, 31-35.

National Diabetes Data Group. Diabetes in America: diabetes data compiled 1984, Bethesda, MD: Public Health Service, National Institutes of Health, 1985: DHHS (NIH 85-1468).

Paulozzi, L. J., Norman, J. E., McMahon, P., \& Connell, F. A. (1984). Outcomes of a diabetes education program. Public Health. Reports, $\underline{99}, 575-579$.

Polit, D., \& Hungler, B. (1985). Essentials of nursing research, Philadelphia: J. B. Lippincott.

Pugh, J. A., Stern, M. P., Haffner, S. M., Eifler, C. W., \& Zapata, M. (1988). Excess incidence of treatment of end-stage renal disease in Mexican-Americans. American Journal of Epiidemiology, 127, 135-144.

Quesada, G. Mi. (1976). Language and communication barriers for health delivery to a minority group. Social Science and Medicine, 10, 323-327.

Reinert, B. R. (1988). The health care beliefs and values of MexicanAmericans. Home Health Care Nurse, 4, 23-31.

Rosenqvist, U., Carlson, A., \& Rolf, L. (1988). Evaluation of comprehensive program for diabetes care at primary healthcare level. Diabetes Care, 11, 269-274. 
Rosenstock, J. M. (1985). Understanding and enhancing patient compliance with diabetes regimens. Diabetes Care, 8 , 610-615.

Rosenstock, J. M. (1974). Historical origins of the health belief model. Health Education Monographs, 2, 328-335.

Saunders, L. (1954). Cultural differences and medical care: The case of the Spanish speaking people of the Southwest. New York: Russell Sage Foundation.

Schade, D. (1982). The Stress factor: If you suspect that stress can disrupt diabetes control, you are right!. Diabetes Forecast, 35, 334-337.

Stern, M. P., Pugh, J. A., Parten-Gaskill, S., \& Hazuda, H. P. (1982). Knowledge, attitudes, and behavior related to obesity and dieting in Mexican-Americans and Anglos: The San Antonio Heart Study. American Journal of Epidemiology, 115, 917 928.

Stern, M. P., Rosenthal, M., Haffner, S. M., Hazuda, H. P., \& Franco, L. J. (1984). Sex difference in the effects of sociocultural status on diabetes and cardiovascular risk factors in MexicanAmericans: The San Antonio hearty study. American Journal of Epidemiology, 120, 834-851.

The California State University, Statistical Package for the Social Sciences, State University Data Center, Version 8.3 (NOS) May 4, 1982. 
U.S. Bureau of the Census, Department of Commerce. (1988). The Hispanic population in the United States: March 1988 (Advance Report), San Francisco-Oakland, CA: U. S. Government Printing Office.

U.S. Bureau of the Census, Department of Commerce. (1984).

Conditions of Hispanics in America today: San FranciscoOakland, CA: U. S. Government Printing Office.

U.S. Bureau of the Census, Department of Commerce. (1983). 1980 Census of Population and Housing - Census Tracts: San Francisco-Oakland, CA: U. S. Government Printing Office.

U.S. Department of Health and Human Services. (1988). Health Care Financing Program Statistics: Medicare and Medicaid Data Book, (HCFA Pub. No. 03270). Baltimore, MD.

U.S. Department of Health and Human Services. (1986). Report of the secretary's task force on Black \& Minority Health Vol VII Current issues in Hispanic health. Chemical Dependence \& Diabetes.

Weaver, J. L. (1976). National health policy and the underserved. Saint Louis: The C. V. Mosby Company. Weaver, J. L. (1973). Mexican-American health care behavior: A critical review of the literature. Social Science Quarterly, 54, 85-102. 
APPENDICES

66 


\section{APPENDIX A}

Approval by Human Subjects

Institutional Review Board 


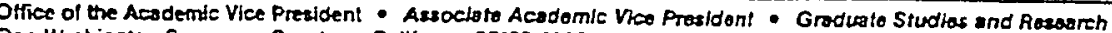

One Washington Square - San Jose. Califomia 95152-0025 • 4081924-2480

Io: Carmen Takacs, Nursing

From: Charles R. Bolz

Office of Graduate Studies and Research

Date: January 22, 1990

The Human Subjects Institutional Peview Board has approved your request to use human subjects in the study entitled:

"A Study of the Effectiveness of a Culturally Modified Health Education Erogram on the Prevention and Control of Diabetes II"

This approval is contingent upon the subjects participating in your research project being appropriately protected from risk. This includes the protection of the anonymity of the subjects' identity when they participate in your research project, and with regard to any and all data that may be collected from the subjects. The Board's approval includes continued monitoring of your research by the Board to assure that the subjects are being adeguately and properly protected from such risks. If at any time a subject becomes injured or complains of injury, you must notify Dr. Serena Stanford immediately. Injury includes but is not limited to bodily harm, psychological trauma and release of potentially damaging personal information.

Please also be advised that each subject needs to be fully informed and aware that their participation in your research project is voluntazy, and that he or she may witharaw from the project at any time. Further, a subject's participation, refusal to participate or witharawal will not affect any services the subject is receiving or will receive at the institution in which the research is being conducted.

If you have any questions, please contact Dr. Stanford or me at $4-2480$.

ce: Enilie Musci, RN 


\section{APPENDIX B}

Consent Form for Experimental and Control Group in English 


\section{Consent Form}

I have been asked to participate in a study conducted by Carmen Takacs, a graduate nursing student at San Jose State University, Department of Health Science. This study is investigating whether a diabetes class culturally designed to meet the needs of the Hispanic client will help to better control their diabetes condition.

The results of this study may contribute to knowledge about educational needs that will help health professionals in the development of better treatment plans for better care of your diabetes condition.

I will be askad to complete a questionnaire about my reactions to my medical care for diabetes. I understand that to answer these questions will take about fifty 50 minutes of my time. I will answer this questionnaire in the classroom assigned at the Senior Center or in my home, always with the investigator, who will provide help to clarify questions, as needed.

My participation in this study is strictly voluntary and l'm free to withdraw my consent at any time without jeopardy to my health services. I understand that any information that 1 provide will be kept strictly confidential and that neither my name nor any other information relating specifically to me will be used in the final report of this study.

I have been informed that I may get tired or discomfort from sitting or trying to concentrate on these questions. I have been instructed to stop for a rest or any other needs that I may have.

If I have any additional questions about the study I may contact Mrs Takacs. Complaints about the procedure may be presented to Emilie Musci, RN, DNS-Advisor. For questions or complaints about research subject's rights, or in the event of research-related injury, contact Serena Stanford, PhD (Associate Academic Vice President for Graduate Studies and Research).

My signature below indicates that I have decided to participate in this study, after reading the information provided above and having discussed it with the researcher.

Signature of Witness

Date
Signature of Subject

Signature of Researcher 
APPENDIXC

Consent Form for Experimental and Control Group in Spanish 
School of the Applied Arts and Scienzes - Department of Nursing

One Washington Square - San José. California 95192-0057 • 408/924-3130

\section{Carta de Consentimiente}

Me han pedido participar en un estudio conducido por Carmen Takass, estudiante hacia el grado de maestria en enfermeria en la universidad de San Jose. Este estudio es para investigar si clases sobre la diabetes que han sido especialmente disenadas para ayudar las necesidades culturales del cliente Hispano ayudaran al mejor control de la diabetes.

Los resultados de este estudio pueden contribuir al conocimiento acerca de las necesidades educativas que ayudaran a los profesionales de salud en el desarrollo de mejores planes de tratamiento para ayudar al mejor cuidado de su diabetes.

Me pedirar completar un cuestionario relacionado con mis reacciones de mi cuidedo medico de la diabetes. Entiendo que para contestar estas pregunias necesito

aproximadamente 50 minutos. Contestare este cuestionario en el salon de clases del Centro de Adultos asignado o en mi hogar, siempre con el investigator presente el cual proveera ayuda para clarificar las preguritas segun sea necesario.

Mi participacion en este estudio es completamente voluntaria y soy libre de rechazar mi consentimiento cuando sea necesario sin problemas futuros. Tambien entiendo que la informacion que yo provea sera estrictamente conídencial y que mi nombre o alguna informacion relacionada especificamente con mi persona no seran usados en el reporte final de este estudio.

He sido informado que me puedo cansar o aburrir en este periodo de tiempo al tratar de concentrar en la contestacion de cada pregunta, pero he sido instruico que puedo parar en cualquier momento para descansar o cualquier otia necesidad que se presente.

Si tengo alguna pregunta relacionada con este estudio, puedo comunicarme con Carmen Takacs. Quejas acerca del procedimiento pueden ser presentadas a Emilie Musci, RN, DNS-Advisor. Preguntas o quejas sobre los derechos del paciente y este estudio 0 accidente reiacionado con este estudio pueden ser presentadas a Serena Stanford, PhD (Vice-Presidente Asociado Academico de Estudios Graduados e Investigaciones.

Mi firma indica que he decidido participar en este estudio, despues de leer la informacion provista y haberla discutido con la Sra. Takacs.

Firma de! testigo

Fecha
Firma del paciente

Firma del investigador 


\section{APPENDIXD}

Approval for Questionnaire Use 


\section{Veterans - \\ Administration}

In Redly Refe: To:

October 24, 1989

Mrs. Carmen Takacs

Sunnyvale, California 94086

Dear Mrs. Takacs:

Thank you for your interest in the Diabetes Health Belief Scale. You have my permission to use the scale in your work. We ask only that you reference our article in any urite-up of your work with the scale. I have also included a copy of the scoring for the scale.

Good luck with your endeavors.

Sincerely,

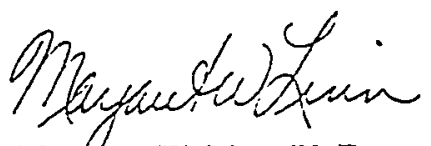

Margere: W. Linn, Ph.D.

Director, Socia! Science Research

MWL/pm 


\section{APPENDIXE}

Diabetes Health Belief Scale 
PLeAse NOTE

Copyrighted materials in this document have not been filmed at the request of the author. They are available for consultation, however, in the author's university library.

76-77

University Microfilms International 


\section{APPENDIXF \\ Approval of Spanish Translation \\ by Foreign Languages Department}


$=\frac{(\text { SAN JOSESTATE UNIVERSITYFOUNDATION }}{\text { SAION }}$

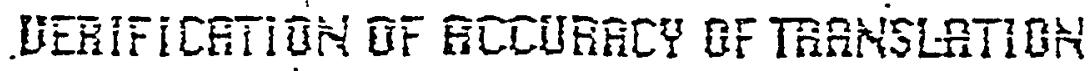

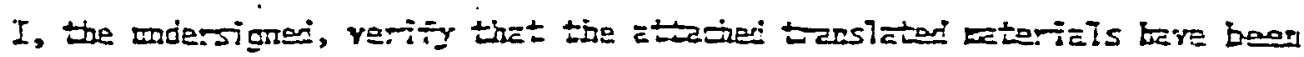

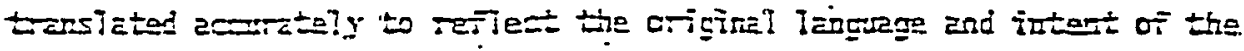
Engisistet.

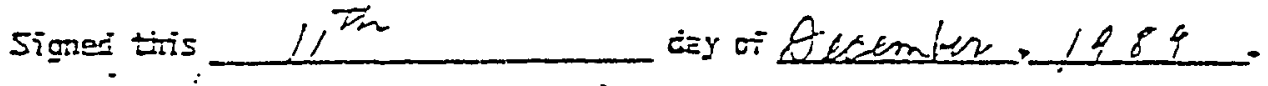

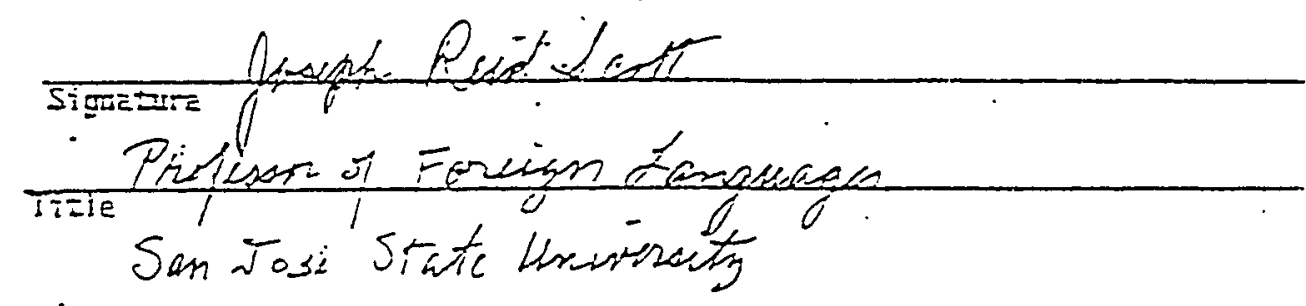

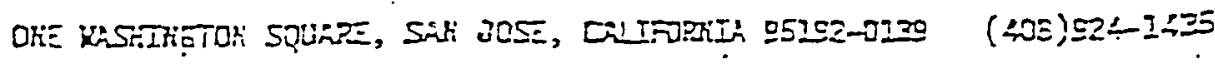




\section{APPENDIX G}

Diabetes Health Belief Scale

Spanish Translation 


\title{
PLEASE NOTE
}

\begin{abstract}
Copyrighted materials in this document have not been filmed at the request of the author. They are available for consultation, however, in the author's university library.
\end{abstract}

$$
\text { 81-83 }
$$

University Microfilms International 


\section{APPENDIXH}

Scoring of the Diabetes Health Belief Scale 


\section{SCORING OF THE DIABETES HEALTH BELIEF SCALE}

\section{SUBSCALES}

General Health Motivation

Treatment Benefit

Severity

Susceptibility

Psychological Barriers

Cues to Action

Structural Elements

\section{ITEMS}

$1,2,11,21,36$

$7,14,16,26,30,37$

$13,17,23,29,33$

$6,8,15,19,22,25$,

$27,32,34,38$

$4,18,24$

$12,28,31,35$

$3,5,9,10,20$ 
APPENDIX I

Demographic Tool 
DEMOGRAPHIC TOOL

Client File \#

Age

Education Level
Physician: Yes

Sex: Male

Diabetes Classes

Nr. Attended

No

Female

Diabetes onset: Years

Diabetes Medical Treatment Yes No

Diet

Oral Medication

Insulin

Family History of Diabetes

Mother Yes__ No

Father: Yes No

Sister:

Yes No

Brother: Yes No

Daughter: Yes No Son: Yes No

Diabetes Complications

Eye disease

High Blood Pressure

Neuropathy (Numbness)

Circulation problems

Skin ulcers

Heart problems

Kidney disease

Recurrent infections

Amputation

\begin{tabular}{|c|c|}
\hline Yes & No_ \\
\hline Yes_ & No_ \\
\hline Yes_ & No_ \\
\hline Yes. & No \\
\hline Yes_ & No \\
\hline Yes_ & No_ \\
\hline Yes & No \\
\hline Yes_ & No_ \\
\hline Yes & No_ \\
\hline
\end{tabular}




\section{APPENDIX $J$ \\ Diabetes Society of Santa Clara County \\ Approval by Education Director}




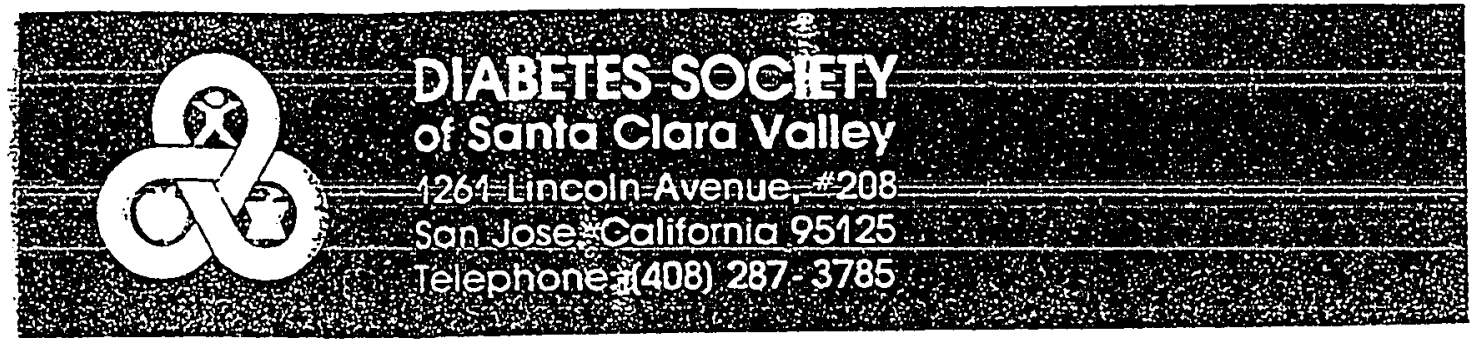

BOARU OF DIRE:TIORS

Mienoel Gleenitel..M.D.

President

Poulitaus:

First Vite Piesiogn

Dorotny Coyne. R.N.

Secont: Viee President

Jonn Me:men W.D.

Treasute

Susen G:ne:mer. R. Sostetory

Fuce fnosiget. is os

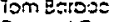

Pronord Ciletin. N.L.

Jusese Levasic sowsids

Montee A Gto:a, Ni.D.

Li:nco Heary

Glots: lew

Miznoe: Liss.jus

Iinco Maseonoi:

Lama: Nes:

Aloer istive

Inge: 5opeidin ?-..

Richore ingerisson

Jessie To:re:

Emsenwe. ws

Sean:s vis:

HONORARY EOMKRE

OF DIRECTORS

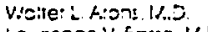

Lovrcnce V' ExssE. I.

Lหmา อenา:

SE.तve: Cong.

Do:!s Conste 7id! R.t.

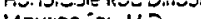

Woulte roh. lo

Roy Hin: L.D.

FeEoy riemin sen

Alion lcvere:. Wu.

Yoya os Lunc katinez

ivioyo indme: ks snery

ree: Mske..n

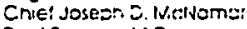

PQul Rosane iv. D.

Jomes Sinse. IV..D.

Dove Visiwor.... Ri:

EXEOUTVE DIREOTOR

Executiv
Dctober 31, 1389

Carmen Takacs

Sunnyvale, CA 54085

Deas Casmer,

You: regearch proposal to do en evaluation of

our Hispani= Educetion Program with resperit to

diabetic regime compliance beginning January 1990

has my whole hearted approval and support.

You may have access to records as needed and

administer questionnejres to class participants

per your research resign.

ts you hnox, the evaluation process of the program neede improvement and I'm very much looking forward to vorking with you or. your pooject. Please don't hesitate to ast if you think I can be of assistance.

Sincerely,

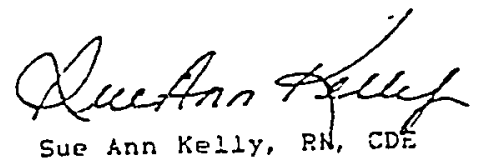

Education Directo:

SAli: Ums 
APPENDIXK

Council on Aging of Santa Clara County

Approval by Site Administrator 


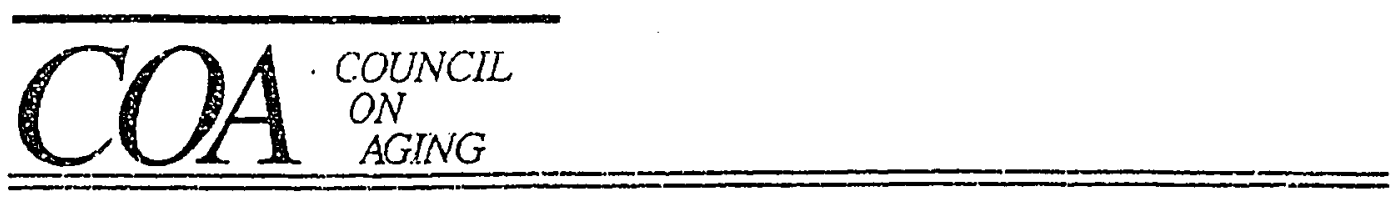

OF SANTA CLAAPA COUNTY, INC. - 2181 THE ALAMEDA - SAN JOSE, CA 95126 *

(408) $296-8290$

October 26, 1989

Mrs. Carmen Tabacs

Sunnyvale, CA 94086

Dear Mrs. Takacs:

Reference your letter dated October 12,1989 . requesting permission to have access to the patient's record to be able to get some demographic data. and to obtain these patients data writh their consent to complete a. questionaire related to their reactions to their self care of diabetes.

I am pleased to grant you permission for your work as described in the above paragrapi.

I wish you the best in your studies and offer my fullest cooperation.

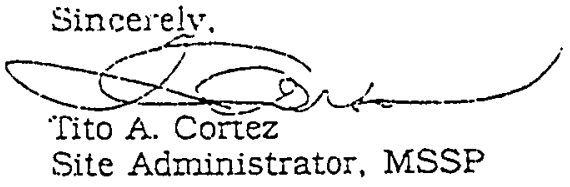

